Portland State University

PDXScholar

7-23-1992

\title{
The Concept of "Communication Skills" in the Discipline of Speech Communication
}

Lynn Bales

Portland State University

Follow this and additional works at: https://pdxscholar.library.pdx.edu/open_access_etds

Part of the Interpersonal and Small Group Communication Commons Let us know how access to this document benefits you.

Recommended Citation

Bales, Lynn, "The Concept of "Communication Skills" in the Discipline of Speech Communication" (1992). Dissertations and Theses. Paper 4221.

https://doi.org/10.15760/etd.6105

This Thesis is brought to you for free and open access. It has been accepted for inclusion in Dissertations and Theses by an authorized administrator of PDXScholar. Please contact us if we can make this document more accessible: pdxscholar@pdx.edu. 
AN ABSTRACT OF THE THESIS OF Lynn Bales for the Master of Science in Speech Communication presented July 23, 1992.

Title: The Concept of "Communication Skills" in the Discipline of speech Communication.

APPROVED BY THE MEMBERS OF THE THESIS COMMITTEE:

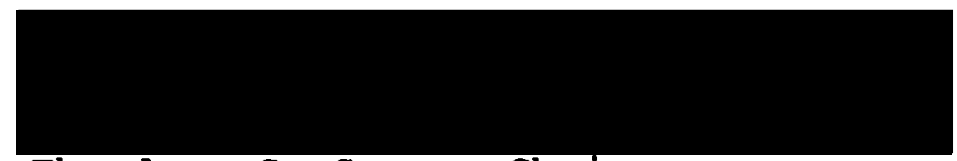

Theodore G. Grove, Chair

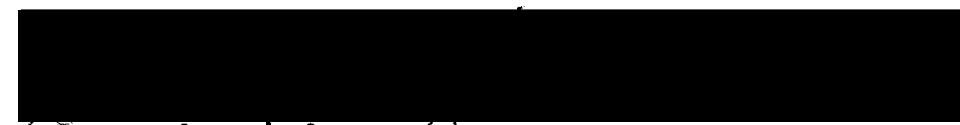

Devorah Lieberman

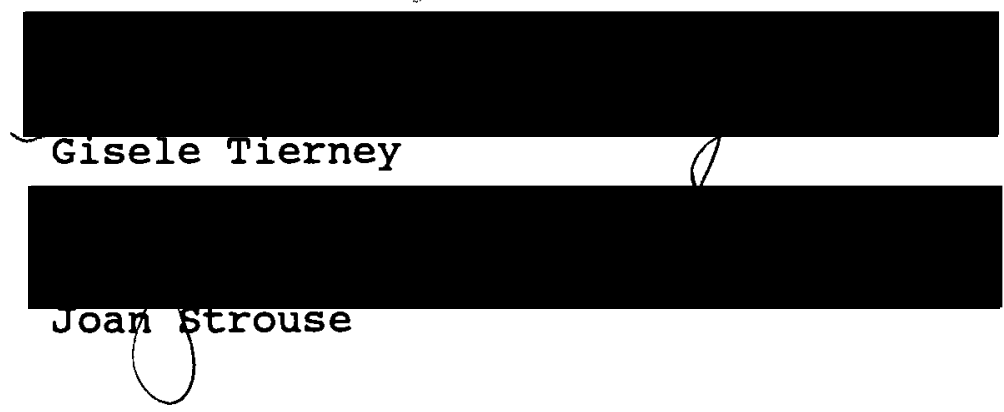

This investigation explored the dialectic of

communication competence from an historical prospective and successfully identified seven common threads in competence theory. Communication skills and skills classifications were linked to competency issues. A content analysis of the 452 page leading national skills level communication text identified 185 skills behaviors along with their associated 
communication competencies. Skills were described in twelve categories; however, no consistent definition or treatment of communication skills was in evidence. Implications of the findings were discussed. 
THE CONCEPT OF "COMMUNICATION SKILLS"

IN THE DISCIPLINE OF SPEECH COMMUNICATION

by

LYNN BALES

A thesis submitted in partial fulfillment of the requirements for the degree of

\author{
MASTER OF SCIENCE \\ in \\ SPEECH COMMUNICATION
}

Portland State University

1992 
TO THE OFFICE OF GRADUATE STUDIES:

The members of the Committee approve the thesis of Lynn Bales presented July 23, 1992.
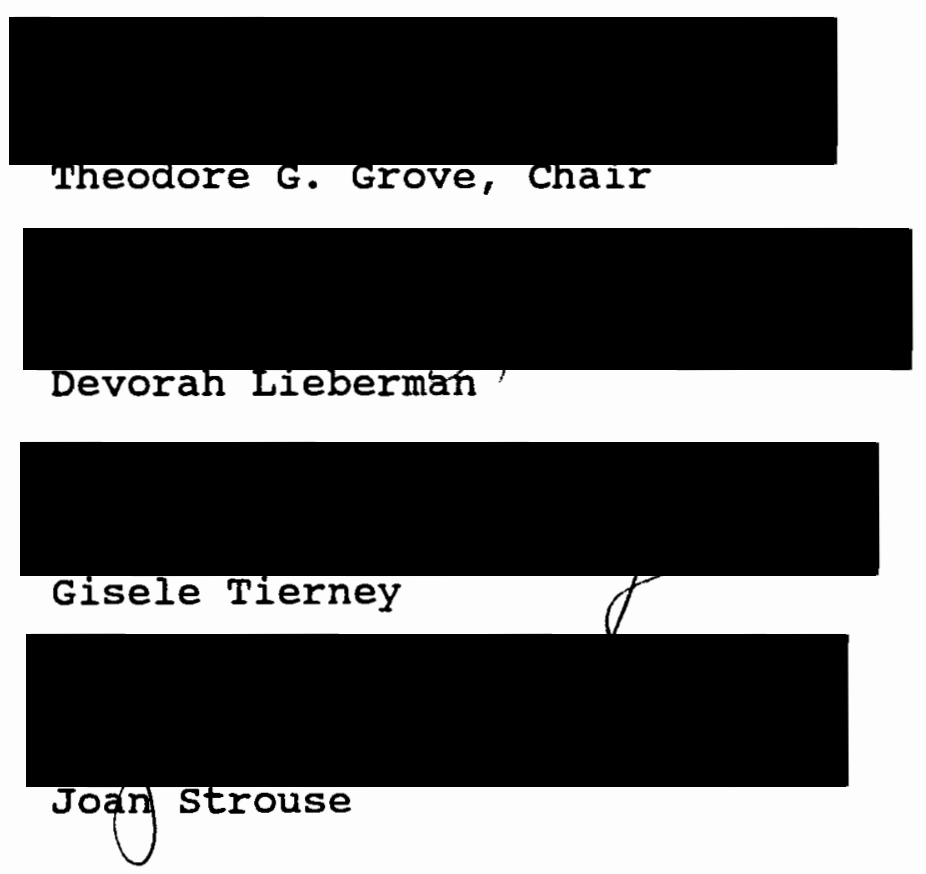

APPROVED :

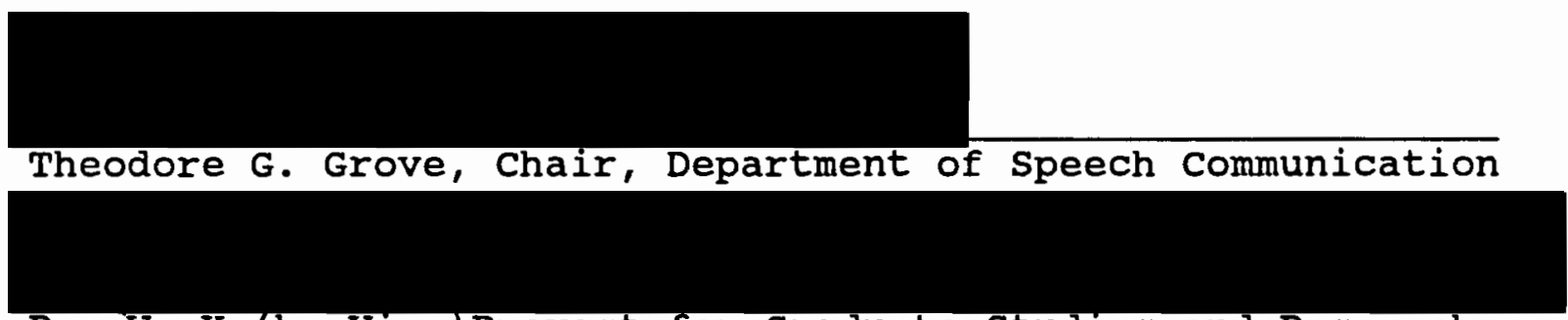

Roy W. Kogh, vice Provost for Graduate studies and Research 
This Work is Dedicated to:

\author{
MY MATE \\ Stephen Bales \\ MY MOM \\ Polly Mabry \\ MY MEN \\ Kip and Bob Hansen \\ and \\ MY MENTORS
}

Trish Rainey-Smith and Theodore Grove 
TABLE OF CONTENTS

PAGE

LIST OF TABLES • . • . • . . . . . . . . . . . . . v

CHAPTER

I COMMUNICATION COMPETENCE . . . . . . . . . . . 1

Review of The Literature . . . . . . . . 1

Common Threads In Competence Theory . . . . 30

II COMMUNICATION SKILLS . . . . . . . . . . 4 42

Control . . . . . . . . . . . . . 42

Classifications of skills . . . . . . . 49

III METHODS . . . . . . . . . . . . . 56

Analysis .. . . . . . . . . . 56

Procedures .......... . . . . 59

IV RESULTS . . . . . . . . . . . . . . 62

Reliability and collating Process . . . . 63

Identification of skills and Paired

Competencies . . . . . . . . . . 65

Context . . . . . . . . . . . . . 74

Summary . . . . . . . . . . . . 74 
$\mathrm{V}$ DISCUSSION •

Implications and Limitations . . . . . . . . . 91

Future Research . . . . . . . . . . . . . . . 97

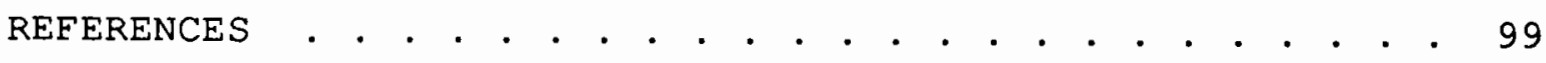




\section{LIST OF TABLES}

I Self Disclosure . . . . . . . . . . 77

II clarification . . . . . . . . . . 79

III Kinesics . . . . . . . . . . . . . 81

IV Paralanguage .. . . . . . . . . 83

$\mathrm{V}$ Eye Contact . . . . . . . . . . . . 85

VI Smile and Frown . . . . . . . . . . 86

VII Proxemics . . . . . . . . . . . . 87

VIII Affect Displays . . . . . . . . . . . 88

IX Silence... . . . . . . . . . . 88

$\mathrm{X}$ Haptics ................. . 89

XI Turn Taking . . . . . . . . . . . . 89

XII Head Nods and Shakes . . . . . . . . . 90 
CHAPTER I

\section{COMMUNICATION COMPETENCE}

The primary thrust of this work is an examination of the construct of communication skills. The intent is to explore and hopefully, clarify the nature of communication skills. Both the frequency and manner with which those within the communication studies discipline refer to this construct suggest that communication scholars confer considerable importance on the idea of communication skills. Yet, as discussed in a later section, no tangible shared concept of communication skills among writers in the field of communication seems to exist. However, before devising a way to approach the subject of communication skills, it is desirable to synthesize the major literature that forms the backdrop for most modern discussions of communication skills. This context consists of the broader and related construct most often referred to as communicative competence (Parks, 1985).

\section{REVIEW OF THE LITERATURE}

\section{Ancient Scholars}

There is a long tradition of concern with making people more competent communicators. Aristotle defined rhetoric as "the faculty of discovering in a particular case what are 
the available means of persuasion" (p.595). To McCroskey, (1982) classical scholars were concerned with the same problems in the definition of competence as those faced by scholars today: the operationalization of competence through rhetoric.

The intellectual descendants of Aristotle have dominated thought concerning both oral and written communication for most of this century, and his [sic] definition of rhetoric could almost pass as a contemporary definition of communication competence. (McCroskey, 1982, p.1)

Aristotle, Isocrates, Cicero, and Quintilian taught and discussed the issues concerning the education of the citizen-orators.

Students were admitted to Isocrates' school of speech at age fifteen. To be accepted, they had to demonstrate competence in science and mathematics and promise in voice control, intellect, and nerve. (cited in Golden, Berquist \& Coleman, 1989, p.54).

Quintilian compiled four volumes on a system of education that would take a person from the early stages of development to the stages of life where polish was the only requirement of an effective orator. He felt that the learning process could not begin too early, nor end too late. Quintilian's ideal of "the good man speaking well" can now be seen as a foundation for what is presently called communicative competence. Effectiveness is looked at as an accomplishment of goals: he discusses the ends-means philosophy. The elements of appropriateness are addressed 
by current scholars and he discussed the appropriateness of the voice when delivering a message, such that

it [voice] should be easy, powerful, fine, flexible, firm, sweet, well sustained, clear, pure, and one that cuts the air and penetrates the ear. One should not hiss, pant, cough, wheeze, or sing. Most of all, vocal tones should be suited to the occasion and to the speech (cited in Golden, Berquist \& Coleman, 1989, p.65).

\section{Contemporary}

Sociological Perspective. Early approaches to communication competence may have come from the ancient fundamentals of rhetorical competencies, but Erving Goffman's (1959, 1967, 1968, 1973) writings on self presentation gave momentum to a modern dialogue on Communication competence. Goffman was a sociologist and worked from a "dramaturgical" perspective or social approach. He analyzed human behavior through a theatrical metaphor, such that the interaction setting is represented as a stage, people as actors, and others as their audiences.

Although the current terminology is different, many of Goffman's concepts address the issues of communication competence. Examples are appropriateness: "maintenance of face is a condition of interaction, not its objective" (Goffman, 1968, p.231); effectiveness: the

usual objectives, such as gaining face for oneself, giving free expression to one's true beliefs, introducing depreciating information about the others, or solving problems and performing tasks, are typically pursued in such a 
way as to be consistent with the maintenance of face $(p .231)$.

Goffman was the prolific social scientist who addressed the situational context of communication interaction, through the idea of selecting appropriate behavior to effectively accommodate each situation. He dealt with impression management and with the social role when he wrote:

his social face can be his most personal possession and the center of his security and pleasure, it is only on loan to him from society; it will be withdrawn unless he conducts himself in a way that is worthy of it (p.230).

Goffman (1967) looked at "other orientation," or empathy when he wrote that a person defends his own face and also protects the face of a listener. The self also acts so as to make it possible and even easy, for the other to employ face-work in a reciprocal manner. "He helps them to help themselves and him" (p.29).

Chris Argyris (1962, 1968a, 1968b), applied his social science background to organizational behaviors, and defined competence as the ability to resolve interpersonal problems. He states that

the competence in a living organism means its fitness or ability to carry on those transactions with the environment which result in its maintaining itself, growing, and flourishing (p.59).

Argyris' conceptions of communication competence, therefore, may be reasonably classified as behavioral. He discussed 
the issues through a theoretical framework which he called "competence acquisition." In his view the objective of competence acquisition was to provide people with opportunities to diagnose and increase their interpersonal competence. Interpersonal competence is the ability to cope effectively with interpersonal relationships. He (1968b) also defined competence as the ability to correct interpersonal problems, but he added the qualification that they be solved "in such a way that the interpersonal relationship is productively maintained" (p.748).

Argyris (1968b) mapped out three criteria for coping with relationships: 1) the individual perceives the interpersonal situation accurately, 2) the individual is able to solve the problems in such a way that they remain solved, and 3) the solution is achieved in such a way that both interactants are still able to work with each other at least as effectively as when they began to solve their problem. He states that

the test of interpersonal competence therefore is not limited to insight and understanding. The individual's interpersonal competence is a function of his ability, and the ability of the others involved, to solve interpersonal problems" (p.748).

Psychological Perspective. From his perspective as a psychologist, Robert W. White $(1959,1968)$ formulated the idea that competence is an issue of motivation and is directly tied to exploring the environment. He defined competence as "an organism's capacity to interact 
effectively with its environment" (p.297). He felt that humans explore the environment, not just because they enjoy novel and complex stimulation, but because the comprehension, understanding, and sense of competence they obtain as a result of exploring is very rewarding to them. People are driven at least partially by their interest in competence and mastery. White (1959) says that

competence means capacity, fitness, or ability. In the human case, effectiveness in dealing with the environment is achieved largely through learning. Competence is an achieved state of affairs in the nervous system which makes effective action possible; and it can be approximately measured in some of its aspects by tests of aptitude, intelligence, and achievement. The subjective side of this can be called sense of competence (p.675).

This fundamental competence is the ability to adapt effectively to the surrounding environment over time to achieve goals (Spitzberg \& Cupach, 1984).

White (1959) developed the theory of "effectance motivation" (p.321) to describe how humans interact with the environment through causing change and being causal agents. As they cause change, they learn from the experience and become more competent. This competence encourages more experimentation, more learning, and consequently more competence. White gives the bases, or foundation, for looking at effectiveness in the competence issue when he states

Every human being is motivated to interact effectively with his environment: the drive to be 
interpersonally competent is the drive to produce effects on or to influence one's world.

Individuals are not effective at birth; social effectiveness is learned throughout life" (cited in Bochner \& Kelly, 1974, p.286).

Although White (1968) does not exclusively discuss communication, he does address the issue of learning to communicate effectively through early developmental trial and error methods. He reiterates with

Interaction with the human environment is a continuous process, but like any other form of development, it tends to have dramatic moments and critical peaks (p.679).

Michael Argyle (1962, 1967, 1968), a British social psychologist, takes a social skill approach and emphasizes effectiveness and appropriateness. He suggests that competence can be studied just as one would study motor skills. He defines skills as

organized, coordinated activity in relation to an object or a situation, which involves a whole chain of sensory, central and motor mechanisms. one of its main characteristics is that the performance, or stream of action, is continuously under the control of the sensory input (p.180).

Argyle (1969) lists components of social competence such as: perceptual sensitivity, warmth and rapport, repertoire of social techniques, flexibility, energy and initiation, and smooth response patterns (p.103). These components, when seen through a communication perspective, also contribute to the dialogue on communication competence. Perceptual sensitivity is described with respect to its effect on the group. 
The most effective leaders of groups have more accurate perceptions than other members, and discriminate between people more sharply. This is particularly true of perceptions of those aspects of behavior which are relevant to the group's purposes (p.103).

Those who show warmth and secure relationships to people will receive the same in return. Those who feel hostile towards people are unlikely to have much success with them, whether they are

pupils, children, or sales prospects. The ability to establish rapport may be partly a matter of learned techniques, and partly of being able to respond rapidly to the social techniques of others (p.103).

A repertoire of social techniques is needed for competence because

it is no good having a sensitive receptor system without the capacity to make the appropriate responses...it has been suggested that he should be 'resourceful' and creative, but a well stocked repertoire will deal with most situations (p.103).

Flexibility is essential, in that

a person who is flexible can get on with a wide range of other people. He should be flexible in the sense of reacting rapidly to the reactions of the other, but he need not necessarily do what the other wants. He is able to deliver other rewards and is able to influence the other in subtle and persuasive ways (p.103).

When discussing energy and initiation, "studies show that people who are very active in social encounters are most effective in them" (p.104). If a person finds the balance in the interaction between energy/initiation and dominance, that person will be more successful in persuasive 
encounters. If not, the dominating person is considered overpowering, not just energetic. Smooth response patterns are important to social competence because

like the practiced performer of a motor skill, the effective social skill performer has a smooth pattern of social techniques. This can only come with long practice or training (p.104).

Linguistic Perspective. Dell H. Hymes' (1971) background in sociolinguistics has enabled him to discuss the rules of language and the cultural norms of speaking communities. He addresses the issue of competence as a sociocultural phenomenon that can not be set up or investigated as rules. Rather one must study beyond language to cultural patterning and social action. Hymes postulates that competence is a matter of cultural knowledge and experience, and is "dependent upon both [tacit] knowledge and [ability for] use" (p.282). In sum,

the goal of a broad theory of competence can be said to show the ways in which the systemically possible, the feasible, and the appropriate are linked to produce and interpret actually occurring cultural behavior" (p.286).

Hymes (1971) discusses how appropriateness is not discussed in linguistic theory, but instead is "lumped" under the heading of performance.

From a communicative standpoint, judgements of appropriateness may not be assignable to different spheres, as between the linguistic and the cultural; certainly, the spheres of the two will intersect (p.286). 
He relates the term "appropriate" to cultural anthropology and extends it to language, but suggests a required sense of relation to contextual features, or "context-sensitive rules" (p.286). He writes of a communicative 'repertoire' which includes three considerations: 1) a set of communicative means (behaviors) and their associated meanings, 2) a set of contexts and their associated meanings in which these means (behaviors) are or can be expressed, and 3 ) the relations among these means and contexts. When a person's communicative knowledge and communication behavior are context-appropriate, they are then considered competent. A person's competence should refer to the ability to perform as well as to the knowledge of how to perform (cited in Spitzberg \& Cupach, 1984) in a given situation.

Communications Perspective. Arthur Bochner and clifford Kelly's (1974) framework for interpersonal competence, a model for speech communication, can integrate the ideals of human interests (humanism) with practical experience (pragmatism) to modify behavior, such that instructional objectives may be developed for increasing communicative competence. Both Bochner and Kelly are from the communication discipline, but study the other social sciences so as to reinforce their argument for a more global definition of competence. They believe that social conditions frustrate interpersonal communication and they look to behavior modification theorists who offer practical 
skills to develop. This is a human relations approach (Wiemann, 1977) to the competence issue.

Bochner \& Kelly (1974) define competence as "a person's ability to interact effectively with other people" (p.288), then go on to define interpersonal competence as a) the ability to formulate and achieve objectives, b) the ability to collaborate effectively with others, to be interdependent, and c) the ability to adapt appropriately to situational or environmental variations.

They delineate five observable skills from this framework that have the properties for successful change, 1) empathic communication, 2) descriptiveness: giving and receiving feedback 3 ) owning feelings and thoughts: assumption of responsibility, 4) self-disclosure, 5) flexibility: the ability to recognize behavioral choices. The thesis for this framework is that "learners should feel competent, and their competence should be observable" $(p .286)$.

Working in Communication Studies, John Wiemann (1977), developed a model by defining communicative competence

as the ability of an interactant to choose among available communicative behaviors in order that he may successfully accomplish his own interpersonal goals during an encounter while maintaining the face and line of his fellow interactants within the constraints of the situation" (p.198). The importance of communicative competence in everyday conversation lies in the role that such conversation plays in the development of the "social identity of the members of any society" (p.196). 
Wiemann discusses interaction management and the concern for the abilities to handle the procedural aspects of structuring and maintaining a conversation. These include negotiation of topics discussed, turn taking, entering and exiting episodes, and handling topical development smoothly. He sets out five dimensions that are indicative of the communication competence definition above which serve as operational definitions of competence that will inform testing, measurement, and instructional strategies: affiliation/support, social relaxation, empathy, behavioral flexibility, and interaction management rules or procedures.

The dynamics of the affiliation/support dimension include the alteration and co-occurrence of specific speech choices which mark the status and affiliative relationships of the interactants, e.g. honorifics: "professor," "Your Honor" and pet names used as markers of a relationship. Eye behavior, head nods, duration of speaking time and number of statements per minute are strong indicators of affiliation. Pleasantness of facial expressing and smiling, statements indicating "Owning" of one's perceptions about another, and physical proximity chosen during interaction are all part of the affiliation/support dimension of interaction management and contribute to their definition of communicative competence. 
Social relaxation is the second dimension of the competence construct. This includes general postural relaxation cues, including rocking movements, leg and foot movements, body lean, the rate of speech and speech disturbances, such as hesitations and non-fluencies, and object manipulations. The third dimension is empathy, in which wiemann included three elements: 1) reciprocity of affect displays, e.g. smiling and other immediacy cues, 2) verbal responses indicating understanding of and feeling for the other's situation, e.g., "I know how you feel", and 3) perceived active listening as indicated by head nods and verbal listener responses or reinforcers. The fourth dimension is behavioral flexibility, or the adaptations one makes within a situation and from situation to situation, which include verbal immediacy cues, and the alteration and color currents of specific speech choices which mark the status and affiliative relationships of interactants.

"Interaction management rules," or procedures, are the fifth dimension which is at the heart of communicative competence. Conversational turn taking synchronization is the ability to smoothly intermesh each participant's speaking turn, thus avoiding simultaneous turns due either to interruptions or both participants beginning a turn at the same time. Topic control is the extent to which each individual contributes to deciding what is to be talked about at any given time during the interaction. Wiemann 
brings up five of these rules: 1) interruptions of the speaker are not permitted, 2) one person talks at a time, 3) speaker turns must interchange, 4) frequent and lengthy pauses must be avoided, and 5) an interactant must be perceived as devoting full attention to the encounter.

Wiemann (1977) is confident that interaction management, affiliation/support, empathy, behavioral flexibility, and social relaxation are interdependent components of communicative competence.

It is by definition that competence is the construct that encompasses the five components; it is a more inclusive, abstract construct than interaction management, empathy, or the other components of the model (p.210).

Wiemann's work on communicator effectiveness takes the emphasis from the speaker judging competence, to the listener/receiver (Diez, 1984). From this view, conceptualizations of communication competence focus less on the qualities or abilities of the speaker and emphasize the perceptions of competence by fellow interactants (Hass \& siebert, 1988).

Wiemann and Backlund (1980) postulate that "the concept of communicative competence has the potential to bridge the gap between theory and performance in everyday social settings" (p.186). They ask several questions that merit consideration when discussing the competence construct: "Is communicative competence a skill? A body of knowledge? An ability?" (p.189) They then set out a system for 
investigating the competence issues that help clarify some elements.

The cognitive perspective has put competence into a category of being a "mental phenomenon" distinct and separate from behavior. Competence is "indicative only of potential performance or capability" (p.187) when classified this way, and theorists taking a cognitive view of competence would hold that "in a strict sense, individuals do not have competence" (p.188).

The behavioral perspective is tied to actual performance of the language in social situations.

The behavioral view of competence, in contrast to the cognitive view, not only seeks an idealized set of rules, but focuses on a repertoire of skills appropriate to a variety of relationships and contexts" (p.188). Behaviorists use a wide range of terms to indicate possession of competence, including "knowledge, skill, ability, awareness, use, and performance" (p.189).

John Wiemann and Philip Backlund (1980) make a case for both behavioral and cognitive perspectives when they state that

the primary consideration appears to be the need to understand the communication abilities necessary for adequate functioning in general society (p.188). If the level of knowledge and skill is sufficiently high, then one may be able to infer that the person is competent, that is, the person can function effectively (p.190).

While the above observations clarify some issues, they do not distinguish the cognitive view from the behavioral. For example, they conclude that communication competence centers on the individual's ability and skill, which 
necessarily includes both knowledge of social/communicative rules and the wherewithal to perform in an appropriate manner.

Wiemann and Backlund (1980) also address the issue of recognizing competence. They feel that competence is socially judged, such that you will know it when you see it.

If the subject was seen as responding appropriately, then he/she was judged as having a degree of competence. This type of social judgment mirrors everyday attribution processes and is necessary to any common sense understanding of communicative competence (p.191).

The criteria for judging competence is here referred to as "appropriateness of behavior" and is determined by "explicit and implicit cultural and group norms, efficacy for attaining a goal, and/or common sense" (p.191). Appropriateness refers to the ability of a person to meet the basic contextual requirements of the situation, to be effective in a general sense. The contextual requirements include:

1) The verbal context, or making sense in terms of wording, of statements, and of topic. 2) The relationship context, the structuring, type and style of messages so that they are consonant with the particular relationship at hand. 3) The environmental context, the consideration of constraints imposed on message making by the symbolic and physical environments (p.191).

James C. Mccroskey (1982), in the field of communication studies, contends that Wiemann's definition of competence as "successful accomplishment of a person's communicative goals" (p.3) is not valid and that the 
accomplishment of goals (effectiveness) is not a condition of competence or even necessary for a person to be deemed competent. McCroskey asserts that performance alone does not indicate that a person is competent and gives this example:

If asked to point to a picture of an elephant, the child may be able to comply; but if one points to the elephant and asks the child what it is, the child may be unable to answer. In contrast, children can be taught to recite the pledge of allegiance or the Lord's prayer long before they have any understanding of what they are reciting" (p.4).

He contends that one cannot conclude competence from performance or foresee performance from competence. McCroskey argued that the term "competence" should be applied to cognitive communication learning and not to psychomotor and affective communication learning.

At this juncture, Mccroskey postulates his definition of competence as "the ability of an individual to demonstrate knowledge of the appropriate communicative behavior in a given situation" (p.5). He is careful to show how communication skills fit into this definition, without obscuring the two definitions. Skills, he claims, are "the ability of an individual to perform appropriate communication behavior in a given situation." He further states that

it is important to stress that our definition of communication skill focuses on the ability of a person to engage in particular behaviors. The 
question is whether the person can do it, not whether they always do do it (p.5).

Mccroskey clarifies his assertions by bringing these definitions into the three "domains of learning": the cognitive (knowledge), the psychomotor (skills), and the affective (attitudes and motivation).

In the cognitive domain, there are three levels: the lower, which consists of specific facts, such as "definitions of communication variables, culturally based nonverbal communication norms, and historical events in the development of the broadcast media," (b) the middle, which focuses on principles and generalizations, as in the "principle of homophily, the relationship between credibility and attitude change, and impact of television on viewer behavior," and (c) the highest, a synthesis and evaluation based on learning at the lower levels, "analyzing an audience, determining an appropriate response to another's interaction behavior, and selecting appropriate appeals to include in an advertisement" (p.5). He feels that this domain encompasses the entire content of the communication field and is the sphere of communicative competence.

The psychomotor domain contains such things as, being able to produce a grammatically correct sentence, to produce the phonemes of the language, speaking without excess vocalized pauses, looking at a receiver in an interaction, and being able to operate a television camera (p.6). 
Within this sphere is where Mccroskey places communication skills.

McCroskey refers to the affective domain as being concerned with attitudes and feelings about the knowledge and behaviors that are acquired through the other two domains. His concerns here are that not enough research has been done in the communication field, and yet the affective domain is at the heart of communication incompetencies. His work in communication apprehension and shyness has reportedly found that focusing on attitudes and feelings has proven to be successful in changing behavior. Therefore, communicative competence research could benefit from the study of this domain.

Brian Spitzberg (1983), also a Communication Scholar, clarifies the competence definition even further when he states that

relational competence concerns the extent to which objectives functionally related to communication are fulfilled through interaction appropriate to the interpersonal context (p.324).

Spitzberg asserts that "relational competence stresses that standards of competence assessment are intrinsic to the relationship in which the communication is enacted" (p.324).

He delineates five assumptions that support his thesis:

1) competence is contextual, what is communicatively competent in one context (relational, chronological, environmental, etc.) may not be in the next, 2) competence is referenced by appropriateness and effectiveness, "this 
suggests that competent communication is best conceived as interaction which accomplishes personal objectives in an interpersonally appropriate manner," 3) competence is judged according to a continuum of effectiveness and appropriateness, "competent interaction is not best conceived as an either-or dichotomy, but as a graduated phenomenon in which individuals are more-or-less competent," 4) communication is functional, "to say that communication is functional is to say that communication does rather than just is," and 5.) competence is an interpersonal impression, which is "resulting from the behaviors of the relational interactants, the context within which they are enacted, and the characteristics of the individuals involved" (p.325326).

After setting out these parameters, spitzberg directly addresses McCroskey's (1982) definition as conceptually containing only four elements: effectiveness, performance, skills, and competence. Spitzberg argues that effectiveness requires performance and that performance needs skills.

Competence, to be maximally sensible and useful as a construct, requires each of these concepts in addition to the constructs of motivation and knowledge. This is sensible because communication is functional, and communication competence involves skill in achieving these functions. Consequently, communication competence involves functional effectiveness (p.326).

Based on their survey of literature, Brian Spitzberg and William Cupach (1984) identified three underlying 
approaches to competence. They consist of 1) outcome focused, 2) message focused, and 3) relational approaches.

outcome Focused. The first approach is outcome focused (social adjustment, skill performance, and goal achievement) with a corresponding deemphasis of the linkage between process and outcome. Fundamental competence, social competence, and interpersonal competence are all concerned with explaining the effective (effectiveness) achievement of outcomes. Out-come focused research is concerned with explaining effective outcomes, while message focused research attempt to explain message behavior. In out-come focused research, Spitzberg \& Cupach reference "fundamental competence" as "an individual's ability to adapt effectively to the surrounding environment over time to achieve goals" (p.35), and reflect two concerns:

(a) the cognitive capacities leading to consistent personal effectiveness, and (b) the developmental processes that facilitate or inhibit the acquisition of general adaptability (p.36).

Fundamental competence describes the general ability to "control the environment through adaptation" (p.70). Elements of performance and skill are assumed, and many researchers use the terms "skills" and "abilities" interchangeably, according to spitzberg, strange as that may seem.

Social competence and social skill researchers also use skills and abilities interchangeably while focusing on the ability to perform certain socially defined roles 
successfully. They identify dimensions that reflect "underlying psychological traits" (p.70). Skills then fall into one of two categories, trait and molecular (state). Trait models view social skills as "relatively enduring personality dispositions," and state models see social skills "as particular, situation-specific behavioral responses, which are not necessarily related to underlying personality characteristics" (p.41). Spitzberg \& Cupach later address these issues as "dispositional" and "situational," because the terms trait and state are imprecise and semantically loaded (Spitzberg \& Cupach, 1991).

Message Focused. The second approach to competence is message focused (appropriateness of messages, either grammatically or contextually), with a corresponding deemphasis of the functional outcomes (effectiveness) of the communication observed. Grammatical or linguistic competence constructs focus on specific forms of appropriateness while another body of work focuses on contextual or social appropriateness.

The social skills state model emphasizes the relationship between specific behaviors and impressions of social skillfulness, which in turn focuses on "notions" of appropriateness and effectiveness and the link between the two. The social skills approach also "attempts to identify 
the normatively or socially accepted behaviors in certain common situations" (Spitzberg \& Cupach, 1984, p.68).

Message-focused approaches link linguistic competence and communicative competence, which they see as a concern of language and message behavior. Spitzberg and Cupach credit Jakobovitz (1984, p.62) with developing a synthesis of linguistic constructs that explains communicative competence. This synthesis includes three forms of meanings or inferences: (a) linguistic meaning which involves, lexical meanings, syntactic relations, and phonological actualization rules, such as, syntactic manipulations, implicit meaning which refers to denotative (precise) and connotative (implied) meanings, and (c) implicative meaning which reflects the psychological state of the speaker, e.g. knowing the difference between a promise and a request. Spitzberg and Cupach (1984) place communication competence under the heading of message-focused approaches because of its interactive message behavior. They define communicative competence as "the ability to adapt messages appropriately to the interaction context" (p.63). They address the Speech Communication Association's project on Speech Communication Competencies of 1976 as containing these perspectives:

1) the exercise of competence depends upon an available repertoire of experiences, 2) it requires that the individual make critical choices from that repertoire, 3 ) it is revealed when suitable behaviors are brought to bear in performing desired tasks, and 4 ) it is sustained 
when individuals are able to evaluate their performance behaviors objectively, thereby enriching their repertoires of experience (p.66).

This suggests that repertoires actually develop to encompass both behaviors and situations. Hymes (1972) alluded to this when he discussed means, meanings, and contexts (see above). Spitzberg goes further to say that "a person's knowledge is indicated by the range of his or her behavioral and contextual repertoire and accurate comprehension of the rules relating these behaviors and contexts" (p.66).

Relational Approaches. The third approach to competence represents a hybrid approach that focuses on the relationship between specific observable behaviors and their outcomes, with respect to both effectiveness and appropriateness. This approach is labeled "relational competence" and, like the social skills models discussed above is concerned with both effectiveness and appropriateness.

Relational competence addresses the issues of effectiveness and appropriateness, and makes the argument that both are necessary to communication competence. Here, Spitzberg and Cupach make the link between communication process and functional outcomes. "One of the most essential features of relational competence is a recognition of the reciprocal and interdependent nature of human interaction" (p.68). This perspective takes an "other orientation," such 
that the person is able to adapt communication

appropriately, be committed to a message, and be an empathic listener. This does not exclude effectiveness, but emphasizes the function of the relationship instead of the message. The key to the relational competence approach is the recognition of interdependence.

Malcolm Parks (1985), a Professor of Speech Communication at the University of Washington, summarizes communication competence research in these words:

In many ways the study of communicative competence represents a set of skills in search of a theory, a set of definitions in search of substance, and a set of theories in search of a uniting metatheoretic construct (p.194).

He chooses to consolidate both cognitive and behavioral perspectives because he sees them as "merely different aspects of the same larger process" (p.174). He continues with

communicative competence represents the degree to which individuals perceive they have satisfied their goals in a given social situation without jeopardizing their ability or opportunity to pursue their other subjectively more important goals (p.175).

This definition emphasizes three themes that he feels are essential to the competence issue:

The first is control,

the notion of control simply implies that people find some consequences of their communication to be more desirable than others and therefore communicate so as to obtain the more desirable ones... [but] we satisfy rather than maximize $(p .195)$. 
The second is responsibility,

to be competent, the communicator must feel responsible for the satisfaction of his or her goals. If one does not feel responsible for producing positive consequences, then he or she will not usually feel competent (p.196).

The third is foresight, competent communicators recognize that their goals are interdependent... [and] have a vested interest in maintaining the rules of social conduct, because they realize, that their ability to pursue their own goals depends on the freedom of others to pursue their goals" (p.197).

The important factor here is the awareness of the interdependence of goals. For example, there are at least two parties in each interaction with the ability to regulate their behavior. Each party will have goals that are not necessarily arranged in a hierarchical pattern. "The pursuit of any one goal may influence the opportunity to pursue other goals" (p.197), such that one party cannot sacrifice all other goals for the obtainment of a single goal. To do so would not necessarily be effective, in that other goals would not then have an opportunity to be satisfied. When both parties are a) aware of "the rules of social conduct" (appropriateness) and b) regulate their behavior for the pursuit of their own goals, c) in a way that accommodates the goals of the other, they are then d) acting in a competent manner. The awareness of both parties' goals and their two fold interdependence is defined by Parks as foresight. 
Many of Parks' contentions are based on a hierarchy of control configuration. He delineates nine control levels and links them to competence.

The first level is intensity control. At this level it is the control of motion of

specific muscles by which all larger behaviors, including speech [and hearing] are produced... it is just sensation or muscle movement and does not contain labels for what is occurring (p.178).

The second level is sensation control. At this level, the information is "packaged" and consists of the individual's ability to accurately sense information and faithfully execute the specific muscle actions required by higher levels in the hierarchy (p.178).

The third level is configuration control. This level encompasses

things like overall body position, movement of limbs, perception of visual forms, and speech at the phonemic level (p.179).

This is still at the unconscious level.

The fourth level is transition control, which

allows us to execute an organized movement such as nodding the head, changing the tone of the voice, or pronouncing a word. It is also what allows us to recognize those same actions in others (p.179). The fifth level is concerned with sequence control, which "allows us to place widely varying concrete behaviors into some sequence" (p.179). This level allows the formation of phrases and allows for the discrimination process, such as the ability to decode nonverbal cues and recognize when messages are incomplete. Another competency 
is "one's skill in timing and placing one's behaviors into the steam [sic] of interaction" (p.179).

At the sixth level is found relationship control. The primary activity of this level is to

detect and behaviorally express the larger relationships among the communicator's actions, the actions of others, and events in the environment" (p.180).

Level seven is the program control, which directs behavior in a given situation and provides predictions and explanations for behavior, thereby helping us reduce uncertainty" (p.182). Programs are goal-oriented; they organize and direct perceptions and behaviors. Programs are scenarios that set up a concept of how things should be, similar to computer software.

Principle control is at the eighth level. This level is "the communicator's abstract goals in a given situation" (p.184). Principles function to choose which programs will be executed, to create new programs, and to evaluate the successfulness of programs in achieving goals.

The ninth level is the system concept control, and is a system of idealized self-concepts. It is at this level that principle and program controls are compared for the evaluation of the self-concept or the development of "guiding principles" (p.186).

People make their own competency assessments at the highest level of the hierarchy. A person's own sense of competence is determined by the ability to satisfy goals and to take responsibility for satisfying them, and by the 
ability to react to failure in a way that promotes satisfaction in the future (Parks, p.187).

Therefore, a conceptualization of competence consistent with the control orientation is proposed by Parks. He views competency as a function of communicators' abilities to specify and attain goals, and argues that competence is best viewed as a characteristic of the control process whereby an individual interacts with the environment, rather than a characteristic (trait) of a communicator. In a discussion by Spitzberg \& Cupach (1984), Parks is credited for identifying six phases involved in effective control: goal specification, information acquisition, prediction making, strategy selection, strategy implementation, and environmental testing (p.54). Differences in the content and structure of these phases account for a person's situational (state) diversity in communication effectiveness. Parks maintains that value perspectives must not be confused with the notion of effectiveness. Dimensions such as rewardingness identity management, empathy, and self-disclosure, which are often identified as components of competence, should not be viewed as general characteristics of competency. Rather, they should be viewed as strategic factors that may or may not be relevant to effective control, given a specific context. Because these factors may situationally conflict with an effectiveness standard, Parks believes that it is useful to distinguish between 
these context-bound strategic decisions and the more general process of effective control.

\section{COMMON THREADS IN COMPETENCE THEORY}

Given this historical overview of the communicative competence literature, several recurring themes in competence theory, including appropriateness, effectiveness, and control, may be extrapolated. Spitzberg and cupach (1984) set out a model of relational competence that is a hybrid of other constructs of communication competence. In their literature review, they formulated their assumptions from the research and ideas of other theorists. According to Devito (1986), assumptions are a "proposition assumed to be true for the sake of deducing inferences from it so that these inferences or consequences may be examined more carefully" (p.24).

Presented here are a few of the common threads, or assumptions, on which the competence issues are based. There is some agreement (Spitzberg \& Cupach, 1984; Spitzberg, 1983; Diez, 1984; Littlejohn, 1982; Van Hoeven, 1985), that each of these issues should be addressed to some degree when describing the construct known as communicative competence. 
Competence is Perceived Appropriateness and Effectiveness

Perceptions of appropriateness and effectiveness support a communicator's credibility. The perception that a communicator has displayed appropriateness and effectiveness suggests that person possesses a certain level of intelligence, knowledge and skill. Perception is the process of becoming aware of objects and events from the senses (DeVito, 1986).

Grove (1991) states that

Effectiveness refers to the extent to which communicative behavior seems to be successful in achieving one's interaction goals. Appropriateness refers to the extent to which communicative behavior reflects verbal sensitivity and is suited to the relational and situational context of the interaction (Wiemann \& Bachlund, 1980). In other words, how is one's interactional conduct viewed by the partner? (p.109).

Spitzberg \& Cupach (1984) state that effectiveness appears to be a common criterion by which communication competence is judged. Typically, effectiveness is conceptualized as the achievement of interactant goals or objectives (Bochner \& Kelly, 1974; White, 1968; Wiemann \& Backlund 1980), or as the "satisfaction of interactant needs, desires, or intentions" (Spitzberg \& Cupach, 1984 p.102). Therefore, effectiveness depends upon the fulfillment of the primary functions of the relationship, 
such as mutual satisfaction, confirmation, consensus, desired change, productivity, and creativity.

Spitzberg \& Cupach (1984) view competence as a construct concerned with quality of communication, in that the competence of a performance refers not only to the ability to perform but also to the ability to perform a task "more or less excellently" (p.104). Therefore, to look to either appropriateness or effectiveness singly as a basis of competence would call into question the excellence of the interaction (Spitzberg, 1983; Grove, 1991). The crux of this assumption is that both appropriateness and effectiveness are necessary and integral to the definition of relational competence, which includes communicative competence.

An individual can behave appropriately but be ineffective; likewise, one can be effective yet inappropriate, and that while appropriateness and effectiveness can be independent, they are likely to be correlated in most communicative episodes" (Spitzberg \& Cupach, 1984, p.106).

The question then arises as to who has the authority to decide that which is appropriate and that which is effective. The interactants themselves are in the best position to perceive if their interactions are appropriate or effective. Appropriateness is a product of cultural and situational acceptance and the perception of what is appropriate is immediate. Effectiveness is a perception of how well and to what extent goals are met, and contextual 
relevance is in the mind of the interactant who is pursuing the goals.

The perception of appropriateness lies with the receiver/partner while the perception of effectiveness lies with the actor/self. A communicator knows when, and to what degree, goals have been met, but the receiver is in a better, or more comfortable, position to evaluate the level of appropriateness of the social exchange (Spitzberg \& Canary, 1985; Canary \& Spitzberg, 1990; Grove, 1991).

\section{Competence is contextual}

While effectiveness and appropriateness are central to competence, they exist, not in a vacuum, but in relation to the context of the event. Context of communication is the physical, social-psychological, and temporal/transitory environment in which communication takes place and which exert influence on the form and content of communication (Devito, 1986).

The crux of virtually any concept of competence is adaptation to given contexts. So ingrained is this dogma that it has become axiomatic in the writings of most competence theorists.... There is an ever increasing literature on the dimensional and typological nature of contexts, suggesting the perceptual centrality of contexts in conceiving the social world (Spitzberg \& Brunner, 1991, p.28).

Communication can be socially appropriate yet quite inappropriate to the specific interpersonal context, and vice versa (Spitzberg \& Cupach, 1984, Canary \& Spitzberg, 
1987). An example is found in assertiveness training, in that assertive statements may be deemed inappropriate if they are perceived as aggressive by the other. The appropriateness of behavior obviously relies on the objective of that behavior in a given situation, but not knowing the appropriate behavior to perform is a potential cause of situational anxiety.

The standards for effectiveness are also influenced by situation. In order to achieve objectives, communicators must follow rules that indicate relevant and efficacious strategies and tactics. "strategies and tactics are enacted to fulfill objectives relevant to the situation" (Spitzberg \& Cupach, 1984), and therefore, effectiveness is contextual (Goffman, 1968; Hymes, 1971; Wiemann \& Backlund, 1980; Spitzberg, 1983).

In a discussion of competence, spitzberg and Cupach (1984) explained the difference between linguistic and communication competence as appropriateness. While some authors have interpreted ability to mean knowledge of that which is appropriate (McCroskey, 1982; Hymes, 1971), others have construed ability to also include skill, or performance of that which is appropriate (Argyle, 1969; Bochner \& Kelly, 1974; Spitzberg \& Cupach, 1984). Communicative competence is distinguished from linguistic competence in two important ways. First, while linguistic competence is concerned with that which is grammatical, communicative competence is 
concerned with that which is situationally appropriate (Hymes, 1971). Thus, while linguistic competence entails knowledge of grammatical rules, communicative competence implies knowledge of cultural, social, and interpersonal rules for acceptability of behavior (Hymes, 1971; Bochner \& Kelly, 1974; Goffman, 1968). Second, because communicative competence embraces the assumption of contextuality, it recognizes that dimensions other than knowledge about language necessarily affect the demonstration of competent communication behavior (Spitzberg \& Cupach, 1984, Spitzberg \& Brunner, 1991). In sum, "communication competence refers to the ability to demonstrate appropriate communication in a given context" (p.107).

Spitzberg \& Cupach (1984) further state that interpersonal relationships engender idiosyncratic rule systems which suggest the importance of viewing appropriateness as a context-specific phenomenon, and that "situational exigencies and constraints determine the appropriateness and effectiveness of communication behavior" (p.107), so as to explain why behavioral flexibility skills (and underlying cognitive processes such as empathy, role taking, and problem-solving skills) are so widely and consistently cited as indicators of competence. "A person must not only possess the ability to enact the behaviors appropriate to a situation but also be able to recognize 
what the situational parameters of appropriateness are" (p.108).

\section{Competence is a Matter of Degree}

When measuring competence, Spitzberg \& Cupach (1984)

found that appropriateness and effectiveness were substantively and positively related when using a semantic differential scale. Words such as satisfying/dissatisfying, effective/ineffective, and successful/unsuccessful, were used to measure effectiveness. Words, such as proper/improper, appropriate/inappropriate, and awkward/smooth, were used to measure appropriateness.

Judgments of appropriateness and effectiveness are not dichotomized, but are arrayed along a continuum. There is no one specific place where a conversation is considered competent, nor another in which it is not. The communication process is dynamic and, therefore, the criteria of effectiveness and appropriateness are then also dynamic, necessitating relative versus absolute judgments. A continuum approach also recognizes that in a given situation, there may be more than one optimal set of outcomes (Spitzberg \& Cupach, 1984). Conversants are seen as achieving a degree of their objectives, not all or nothing.

Consistent with the continuum assumption is the fact that communication performance can vary from episode to episode (within similar contexts), from 
situation to situation (between contexts), and even within a particular episode (p.110).

\section{Competence is Both Molar and Molecular}

The term molar refers to general or holistic evaluations while the term molecular refers to specific or atomistic evaluations. In practice, instruments proposing to measure communicative competence can be viewed as occupying different points on a continuum, from molar to molecular. Molar impressions provide evaluative outcome criteria. Items such as "openness" and "expressiveness" are both subjective and global and are considered molar items. Molecular references to specific behaviors provide a link between conceptions of communication competence and the specific skills whereby one achieves a given level of competence. Molecular items focus on relatively discreet, specific behaviors such as "used hand gestures frequently." The implication of the molar/molecular distinction concerns the generalizability of a study. The more molar the item composition of a measure, the more applicable are the results to a variety of communicative encounters. However, the more molar the item composition, the less useful the measure for providing specific information regarding the precise nature of an interactant's proficiencies and deficiencies (Spitzberg \& Cupach, 1984; Haas \& Seibert, 1988) . 
Competent communication is Functional

To view communication as functional is to view the process as related to and productive of functional outcomes (Spitzberg \& Cupach, 1984, p.112). Communication behaviors act to affect, alter, or accomplish goals of controlling, feeling, informing, ritualizing, and imagining (p.113). Effective identity-related communication, because it maintains, repairs, or enhances self-concept, should result in perceived confirmation (p.113).

Competent communication is functional in that communication does rather than just is (Spitzberg, 1983), or that messages "do" rather than simply "are" (Spitzberg \& Cupach, 1984, p.112). In other words, competent communication functions so as to confirm or reinforce one's image of self and other. Communication, in general, functions to produce certain outcomes. Functionality is to communication that which achieving goals is to effectiveness.

People accomplish ends through communication, intentionally and unintentionally. Messages are functionally related to communication effects, however transient and seemingly intangible. Consequently, to view communication as functional is to view the process as related to and productive of functional outcomes (p.112).

Allen \& Wood (1978) delineate five communication functions that they feel are central to contemporary life: controlling, sharing feelings, informing, ritualizing, and imagining. When a message is sent, one or more of these functions are included, although it may not be the goal of the speaker to do so.

For example, we may present an exciting challenge (sharing feelings) in our attempt to enlist someone's help on a project (controlling). or, in our attempt to answer the question "How was your 
dinner last night?" with the details of the evening (informing), we might describe or even role-play the behavior of the clumsy waitress who couldn't do anything correctly (imagining). Communication events are usually multi-dimensional in terms of function (p.288).

White (1968) postulates that since competent communication is perceived to be appropriate, it should not significantly violate the other interactant's sense of self. Further, effective communication is reinforcing and gratifying to a person's need for efficacy (power to produce desired results or effects). Consequently, competent communication should be confirming. This expectation has been supported strongly by research on relational competence (Spitzberg, 1982). Communication functions as a means to self confirmation, reinforcement and gratification. Identifiable functions indicate identifiable criteria outcomes of competent interaction. "Given the contextual nature of competence judgements, a given behavioral sequence can be assessed as competent only if it is related to functional outcomes of competence" (Spitzberg \& Cupach, 1984, p.113).

Competence is an Interdependent Process

Competent communication goes beyond recognition and evaluation of the speaker to recognition that the interdependence of the interactants is necessary, because an individual is competent only in the context of a relationship. 
competence lies in the relational system.

Consequently, judgment of competence can only

validly be made in terms of systemic

effectiveness, appropriateness and satisfaction

(Wiemann \& Backlund, 1980, p.189).

As Wiemann (1977) argues, one may be personally

effective in achieving goals but "may be incompetent in an interpersonal sense if such effectiveness precludes the possibility of others accomplishing their goals" (p.196). Parks (1985) defines this interdependent awareness as foresight, and states that competent communicators

have a vested interest in maintaining the rules of social conduct because they realize, however dimly, that their ability to pursue their own goals depends on the freedom of others to pursue their goals (p.197).

\section{Competence is an Interpersonal Impression}

Competence is not something intrinsic to a person's nature or behavior; it is an impression that a person has of self or other. This impression is based on the behavioral minute of a given episode and the history of the relationship that contextualizes the behavioral choreography enacted within it (Spitzberg \& Cupach, 1984, p.115).

Relational competence focuses on the perception of competence by the participants in a given conversation and relationship (Spitzberg \& Cupach, 1984; Goffman, 1968). Competence is not an inherent characteristic of another person that a third party is able to observe. Competence is an impression resulting from the behaviors of the relational interactants, the context within which they are enacted, and 
the characteristics of the individuals involved (spitzberg, 1983).

Concluding Remarks

To assert that the assumptions listed above are all inclusive would be an understatement. To analyze competence as being perceived appropriateness and effectiveness or contextual, impressionistic, functional, a matter of degree, molar and molecular, or an interdependent process only serves to frustrate attempts at a coherent definition. Parks (1985) indicates that

$$
\begin{aligned}
& \text { the theoretician's challenge is all the more } \\
& \text { frustrating because the concept of competence } \\
& \text { touches nearly every corner of the study of } \\
& \text { communication (p.194). }
\end{aligned}
$$

Fortunately, and as indicated at the very outset, communication competence is merely the backdrop for the construct of communication skills which furnishes the focus for this investigation. Following this survey of major contributions to communication competence theory, Chapter Two focuses more narrowly on communication skills and the purpose of the present investigation. 
CHAPTER II

COMMUNICATION SKILLS

CONTROL

\section{Control and Regulation of Interaction}

As presented in the previous section, communicative competence is most often interpreted in relation to effectiveness, appropriateness, and related constructs. In turn, the achievement of goals (effectiveness) in an appropriate manner is the domain of control (Parks,1985; Spitzberg \& Cupach, 1984; Grove, 1991). In interpersonal conversations, the parties have the opportunity to make numerous choices with respect to behaviors that regulate the content, flow, and structure of interaction. Examples of such interaction-regulating behaviors can be observed with respect to processes such as interactional immediacy, reciprocity, and compensatory responses.

Immediacy. The concept of immediacy maintains that people approach, or become involved with, those people and objects that they like and avoid people and objects that they do not like, such that the level of self-disclosure, amount of eye contact, proximity, and topic switches can 
increase or decrease the chances of achieving effectiveness and appropriateness (Devito, 1986). Spitzberg \& Cupach

\section{(1984) write that}

the effective communicator conveys a sense of immediacy, a sense of contact, of togetherness. This person communicates to others a feeling of interest, an attentive attitude, a liking for and an attraction toward the other person (p.164).

Immediacy is a reflection of closeness and may be measured by verbal and nonverbal behaviors, such as the amount and intimacy of touching and directness of speech.

Reciprocity and Compensatory Regulations. Interactants have the opportunity, with each new interaction, to be responsive: either reciprocating the partner's behaviors, or compensating for the partner's behaviors (Grove, 1991). Such choices pertain to wide ranging behaviors, such as self disclosure intimacy, vocal rate, loudness, conversational topic, eye gaze, proximity, gestures, and smile. By these behaviors, reciprocity and compensatory reactions serve to regulate, or control, moment-to-moment interactions and complete conversations.

\section{Control and Awareness}

Whether control refers to microscopic segments of interaction, to entire conversations, or to whole dyadic relationships, control has been equated with management. Capella (1985) writes: 
The typical connotation of the word "manage" implies that a person intentionally seeks to alter the content, tenor, or events of a conversation toward some preordained end or purpose. Management [can] exhibit "control" in the sense that actions are undertaken in order to achieve what one perceives to be an important need or purpose [or goal]. The ability to control conversations depends upon the existence of certain regularities that can be exploited by one or the other conversational partner, and this exploitation depends upon knowledge of the regularity. Once made aware of such regularities, people could use them to manage the content and style of their conversations. (p.393).

Requlation of Interaction. Grove (1991) writes that "Regulating our interaction through increasingly appropriate means to achieve increasingly effective outcomes has been emphasized...throughout the literature on communicative competence" (p.333). Regulation of interaction, or interaction management, is the process by which an interpersonal interaction is orchestrated, coordinated, and regulated. It also represents the process by which an interaction is initiated, maintained and terminated, and the extent to which an interaction, in all its phases, is satisfactorily controlled (Devito, 1986).

The basic elements of the regulation of interactions are self awareness and other awareness (Parks, 1985). Self awareness is not constant or enduring, but situational, such that each new encounter will highlight a different facet of the self. Consciousness of what we are doing allows us the opportunity of doing it better (Grove, 1991). 
What we are doing (behavior) is delineated in two ways: by choice (awareness) and by automatic impulses (out of awareness, or unconscious). Choices in behaviors are regulative instruments which can be used to control the levels of immediacy.

The only difference between the regularities that people consciously employ to control conversations (for example, topic continuity) and those that they do not (for example, speech rate) is that conversationalists are not generally aware of many of the regularities that do govern conversational events. (Cappella, 1985, p.393)

\section{Control, Competence, and Skills}

Researchers have focused on the control, or regulative feature, of communicative competence in connection with momentary interaction (Goffman, 1959; Argyle, 1969; Wiemann, 1977 ), conversations (Hymes, 1971; Bochner \& Kelly, 1974; Spitzberg \& Cupach, 1984), conflict episodes (Cappella, 1985; Grove, 1991), and other specific events. In all cases, such control is achieved by that which is generally referred to as communication skills. A wide range of skills have been addressed (Bochner \& Kelly 1974; McCroskey, 1982), but some scholars describe specific behaviors that are an integral part of the control domain (Cappella, 1985, Bochner \& Kelly, 1974), such as turn taking, paralanguage, kinesic behaviors, and verbal management.

Turn Taking. Turn taking is the conversational behavior in which interactants exchange the roles of source 
and receiver. Turn taking cues, raising an index finger, opening one's eyes wide, pursing one's lips, verbal starts such as "I..." or "mm-hmm" are verbal and nonverbal behaviors that communicate the desire to exchange the roles of source and receiver (Devito, 1986). Turn taking provides for reciprocity, or reciprocated behaviors, between the interactants, and includes the skills of initiating (understanding demand tickets), maintaining (turn taking) and terminating (signals of inaccessibility) individual transactions, regardless of the level of formality.

Management of Vocal Behaviors. Vocal behaviors, or paralanguage, are the use, or control, of the vocalnonverbal dimension of speech. It is the manner in which something is said rather than what is said. The four major classes of paralinguistic behaviors are 1) voice qualities (specifically pitch range), 2) vocal characterizers (laughing/crying, yelling/whispering), 3) vocal qualifiers (variations in pitch intensity), and 4) vocal segregates (such as uh-uh, \& sh) (Devito, 1986). Evidence has shown that during interaction, vocal reciprocity or matched behavior is the predominant form of mutual influence (Capella, 1985).

Management of Kinesic Behaviors. Management of kinesic behaviors as a conversational regulator consists of the movement of the body as it applies to posture, proximity and gesture, facial expression and eye gaze (Wilmot, 1987). In 
his study of management behaviors, Cappella (1985) found that as proximity increased, so did the level of compensatory effects, such that as proximity (closeness) increases, the other increases distance; as the time it takes to leave the situation increases, the other's eye gaze decreases and the orientation becomes less direct. Proxemic behaviors have been classified into eight general categories: 1) postural-sex identifiers, 2) sociofugalsociopetal orientation, 3) kinesthetic factors, 4) vision, the ability see and read nonverbal cues; 5) thermal factors, 6) loudness, 7) smell or olfaction, 8) haptics or touch (Devito, 1986).

of equal importance to the management of kinesic behaviors, is eye gaze. Eye gaze is a behavior involving the amount and the type of visual contact taking place during an interaction. Four major categories are identified: 1) sharp, focused directly on the other person's eyes; 2) clear, focused about the other person's head and face by not the eyes; 3) peripheral, having the other person within the field of vision but not focused on the head; and 4 ) and no visual contact, looking at the ceiling or into space (Devito, 1986). "Research shows an overall tendency toward reciprocity in gaze in social settings that have a neutral to positive affective tone but a reversal in this trend for settings with negative affective tone" (Capella, 
1985, p.408). Generally, eye contact is reciprocated during interaction and is a strong management tool.

Management of Verbal Behaviors. Management of verbal behavior is the most thoroughly researched of the control skills addressed, as it includes behaviors such as selfdisclosure, topic management, and linguistic features. These behaviors can elicit reciprocity and compensatory responses which regulate conversations by changing the level of immediacy. Self disclosure occurs when personal/private information about the self is communicated to another person. Self disclosures can be overt statements pertaining to the self, as well as slips of the tongue, unconscious nonverbal movements, and public confessions. Only new knowledge is useful. The speaker takes a risk, putting self-esteem in jeopardy, and reveals something significant about who she is and not merely what she has done (Devito, 1986). The level of self-disclosure is almost always reciprocated (Capella, 1985).

Topic presentation, continuity, and management are important to both self and other, in that topics are statements about themselves or the relationship, and topic switches are perceived to be dominant acts.

By letting other persons initiate and maintain their own topics one can show deference to the other, importance of the other's interests, and friendliness and competence in remaining with the introduced topic. At the same time one's own needs for autonomy and attention to problems and concerns must be balanced against attention to the other's topical focus (Capella, 1985, p. 412). 
Linguistic features, such as choices of dialect, pronunciation, grammatical and verbal complexity, are important in judgments of power and status, in seeking and giving approval, and in showing solidarity and separateness. The literature on this topic demonstrates that people match, mismatch, and maintain a variety of linguistic features depending upon the social situation (Cappella, 1985). "Language style helps to establish the impression of intimacy level in the interaction, and changes in style seem to accompany changes or wished for changes in the relationship" (Grove, 1991, p.62).

\section{CLASSIFICATIONS OF SKILLS}

In theoretical discussions, skills are generally divided between the cognitive and behavioral domains. However, there is a definite overlap between the two. For example, while a particular level of "empathy" refers to a cognitive state, the condition of empathy is always inferred from a particular combination of observed verbal and nonverbal behaviors. Furthermore, researchers often differ in their categorizations of skill. Some scholars describe skills on a more global level. For example, Wiemann (1977) labeled regulatory skills as supportiveness, social relaxation, empathy, behavioral flexibility, and interaction management. Capella (1985) argues that 
being able to get control of the floor, keep that control when necessary, and give it up when finished is a crucial interpersonal skill related to perceptions of power, perceptions of affiliation, and to general social competence (p.402).

Concerning the nature of skills in general, Fine (1986) writes:

"Skills relate to 'how to' functions in the things, data, people, hierarchies, of functional job analysis. They are expressed as gerunds, thus serving as both nouns and verbs" (p.65).

\section{Labels for Skills}

Skills have also been divided among relational, speaking, and listening skills. Discussions about interviewing skills and nonverbal skills have been couched in and around those headings. Bassett, Whittington, and Spicer (1978) isolated four competence areas which comprise the skills that high school graduates should possess: 1) communication codes, (ability to use and understand spoken English and nonverbal signs), 2) oral message evaluation (ability to use appraisal standards to judge oral messages and their effects), 3) basic speech communication skills (ability to select and arrange message elements to produce spoken messages), and 4) human relations (ability to maintain interpersonal relationships). The four main skills areas were partitioned into nineteen specific competencies and examples of applications of these were provided for three contexts: occupational, citizenship, and maintenance. It is essential that a person know how to listen, how 
to disclose thoughts and feelings, and how to express that which is true, or situationally relevant. Understanding body language, decoding paralanguage and metamessages, uncovering hidden agendas, and clarifying your and others' language can be difficult, but comprehension of assertiveness, fair fighting, and successfully negotiating in conflict situations can be baffling. Whether or not these processes qualify as communication skills will be addressed in this study.

\section{Purpose}

The need to identify and assess skills has been well documented over the past twenty years (for example: Bochner \& Kelly, 1974; Bochner \& Yerby, 1977; Allen\& Wood, 1978; McCroskey, 1982; Spitzberg, 1983; Wiemann, 1977; Samter \& Burleson, 1990). Notwithstanding, the profusion of writing and theorizing about communication skills within the academic discipline of communication, there still remains a need to identify communication skills that will translate to the business community as job skills (Backlund, et el, 1982; Rubin, 1982; Trank, \& Steel, 1983; Muchmore \& Galvin, 1983). The need for teaching communication skills that will translate to job related communication skills has also received much attention (Muchmore \& Galvin, 1983; Becker \& Ekdom, 1976; Engler-Parish \& Miller, 1989). 
The present project entails a primary assumption and two questions:

Assumption: "Communication skills" refers to purposeful behavior (the means) that one employs to attain desirable outcomes or competencies (ends).

Question 1. What observable behaviors constitute "communication skills?"

Question 2. What specific outcomes, or competencies, are associated with such skills?

While not representing the view of all theorists in this area, the means/outcome distinction in the above assumption is compatible with a majority of the positions surveyed. of equal importance, use of the terms "communication skills" and "communication competencies" hereafter, will reference that distinction.

Any single examination of the possibilities suggested by the above two questions must necessarily be limited so as to arrive at useful and interpretable results. The success of this effort will rest on the degree to which one narrow method of approach is selected from among the many alternatives. One focused approach, with no claim to comprehensiveness, will be used to explore the central questions. 
Justification

A tightly focused investigation of communication skills and their associated competencies will provide some useful information for the following areas.

The Speech Communication Discipline. Even a superficial perusal of speech communication literature provides the reader with the impression that the subject of "communication skills" is very significant in the field of communication studies. This is true regardless of whether the reader is scanning textbooks, articles in scholarly journals, or the texts of conference papers. While references to "communication skills" abound, few definitions are found. Without common definitions or criteria for what constitutes "communication skills," both student efforts aimed at acquiring those skills, and teacher efforts to instruct in those skills will be necessarily unfocused and inefficient.

Employment cultures. When reading through the Employment section of a current newspaper, the phrase "Excellent communication skills required" appears with remarkable frequency. This experimenter (E) has yet to find the phrase defined within the body of any advertisement, so the prospective employee must do some investigating in order to determine these skills. Does the prospective employee 
have them, and if not, can they be learned? Where can these skills be accessed?

Society at Large. There is a need for communication skills throughout all segments of life, not only in business and government agencies, but in social groups, within families and among friends. Therefore, a focused understanding of communication skills will provide useful information and guidelines for functioning throughout the various spheres of our social structure.

Any single examination of communication skills and their associated competencies will certainly not address all the ambiguities in this area, but this paper may provide some guidance in the development of future communication pedagogy. This research area will be of special interest to those who construct curricula for undergraduate students seeking the basic skills needed to communicate successfully.

As a first step toward a more refined understanding of communication skills, an examination of texts that propose to teach communication skills is a reasonable effort. Forecasting the method explicated in the next section, a content analysis of a text from a communication survey course could provide a basis for clarifying the links between communication skills and communication competencies. The questions have been posed: What comprises "communication skills?" How are skills and competencies linked together? 
What language is used in the identifications and the linkages? 
CHAPTER III

METHODS

ANALYSIS

In this chapter will explicate the methods of this investigation are explicated under three headings. First, the domain of the analysis which furnished the contextual subject matter as described for the study is specified. Second, selection of the representative text is presented along with the rationale for that choice. Third, the procedures, scoring units, and other specifications of the content analysis to be performed are described.

\section{Domain of Analysis}

The domain chosen for this inquiry is represented by the basic introductory course in speech communication. In the United states, the introductory course is referred to by textbook publishers as the "hybrid" course, because its subject matter reflects all of the various topical subdivisions that faculty consider to have a primary importance in the academic discipline of speech communication. The material presented in this course is 
considered to be at the "skills" level by Departments of Speech Communication. For example, a typical description for the content of the basic course is:

INTRODUCTION TO SPEECH COMMUNICATION - An Overview of major topic areas of speech communication, including models of communication, social uses of language, nonverbal communication behavior, listening and communication in interpersonal, group, intercultural, public, and mass media contexts (PSU Bulletin:1991-92, p.288).

To those who seek training in communication skills, this class offers an overview of the most diverse set of contexts, and offers exposure to the widest variety of concepts. It is universally required for speech communication majors. The introductory course is meant to provide a foundation for further study of speech communication and, as such, forms that body of material which comes closest to receiving universal approval as appropriate subject matter for students seeking a degree in speech communication.

\section{Sampling of Textbook}

Textbooks are selected by instructors responsible for teaching a given course or by a committee of instructors designated by the faculty of speech Communication departments. The text must meet standards for readability, comprehensiveness, and other criteria, and authors must consider these standards when composing the text. Texts are not necessarily written solely for the end consumer, the 
student, but must also be written with textbook selection processes in mind. The approval of the author's

disciplinary colleagues will determine how many students, if any, will use the text. For a text to pass the scrutiny of so many professors, instructors, and/or committee members and become a "best seller," it must compete favorably with dozens of rival texts written for the same market segment. For a text to be considered truly successful, it must be ordered repeatedly, and consequently continue into multiple editions over a number of years.

Two representatives of major national publishing houses (Brown \& Benchmark and Prentice Hall) were interviewed by telephone, and questioned about the most successful texts available. Each inquiry produced the same findings, given the cluster of available texts. Adler \& Rodman's (1991) Understanding Human Communication, fourth edition, has been the most widely used fundamental text for the last 11 years, with sales "far and away" more than Taylor's (1992) communicating, which is in its sixth edition and Tubbs \& Moss' (1987) Human Communication, which is going to its fifth edition. Furthermore, both respondents indicated that Adler \& Rodman's book would be designated as the leading seller in the field by any knowledgeable publishing representative. 
The text selected for analysis was Adler \& Rodman (1991) Understanding Human Communication, Fourth Edition. The authors touch upon the issue of skills by stating:

Like its predecessors, this edition of Understanding Human Communication refuses to take sides in the "theory vs. skills" debate that seems to rage endlessly within the discipline. The cognitive and behavioral goals that open each chapter show that students will cover both domains of the subject, learning more about theory and research on face-to-face communication and developing skills that will help them communicate more effectively in their lives. Activities in every chapter give students a chance to develop their understanding of communication principles and practice communication skills (p.v).

Although Adler and Rodman do not directly address competencies in the preface, they do address skills. Exploration of the questions set forth in the "Purpose" section of this report, consisted of a content analysis of the 452 pages of text comprising the body of Understanding Human communication.

\section{PROCEDURES}

\section{Content Analysis}

Manifest Content. This study has analyzed the visible surface content of each section of the Adler \& Rodman (1991) text, Understanding Human communication. The data were coded if it is identified as a communication skill and has an identifiable linking with a communicative competency listed in conjunction with the skill. That is, if it is an 
observable behavior that the author relates to an end result, it was be coded. If there was no mention of an end result, it was not counted. A direct means/end linkage was the heart of this investigation.

Latent content or underlying meanings were not coded for this research. The need to analyze communication skills at the latent level is beyond the scope of this investigation, but is encouraged for future researchers.

Language the Author Uses. The language or vocabulary used by the authors when addressing a communication skill and communication competence was noted during the coding exercise. The definitions of the terms the authors use was then cross-matched to the glossary of the text in the final analysis.

Larger context. The context in which the skill was discussed has also be noted. For example, if a skill was addressed in a section on small group communication, that context would be recorded. Instances of skill language that were not assignable to any particular context was then recorded as well, and the lack of context noted.

\section{Coding Schema}

Sampling Unit. The sampling unit consisted of a three sentence segment of text incorporating the sentence immediately preceding and following the sentence in which the scorable unit (behavior) occurred. 
Scorable/Recording Unit. A scorable unit is a word or phrase that represents a behavior and its outcome.

Skills. (1) An observable behavior (2) that is discrete (3) that is teachable and (4) that is employed to attain a desired outcome (competence). If the author does not address an associated outcome, the data was not coded.

competence. (1) The outcome (2) associated with a codeable communication behavior (3) and that is identified by the author or coder as a communication competency. If the author did not address an observable behavior in connection with the competency, that event was not coded.

context. The overall communication context within which the authors described the communication behavior and its associated outcome.

\section{Rater Training and Reliability}

The content analysis proceeded as follows. Subsequent to rater training in the utilization of the coding rules described here, the experimenter, hereafter known as $\mathrm{E}$, selected a text page at random from another current introductory text and began applying the working rules for this content analysis. When 20 recordable units had been found and entered on the coding sheets, the second rater independently coded the same segment of text. Raters compared and discussed the results. At that point, $E$ modified the rules by removing ambiguities, when necessary, 
and $E$ and the second rater proceeded to code, independently, another short segment of text. Upon achieving sufficiently high inter-rater reliability, appropriate coding rules were adopted and $E$ applied them to the 452 pages of the Adler and Rodman text.

An individual with an educational background in linguistics was introduced to the coding rules and, concurrently with $E$, applied them to an introductory communication text other than the target text. Trial coding and rule revision proceeded as described in "Procedures." The final coding trial furnished data for inter-rater reliability, which was calculated from rater agreement on instances of skills identification as follows: Percent Agreement $=\frac{\# \text { of compatible identifications }}{\text { total \# of unique units coded }}$ Intra-rater consistency was assessed by comparing E's final reliability trial with E's recording of that identical text segment after an interim of no less than 10 days. Based on these data, intra-rater reliability was calculated according to the procedure used for inter-rater reliability, noted above. 
CHAPTER IV

RESULTS

This section will present the results of the content analysis of Adler \& Rodman's (1991) Understanding Human Communication. First, the inter-rater and intra-rater reliability of the analysis will be discussed. Second, the categories within which the skill behaviors and their associated outcomes emerged will be defined, the research questions addressed in the tables, and a narrative description of what the category contains will be included. Third, a summary of the results will be presented.

\section{RELIABILITY AND COLLATING PROCESS}

\section{Reliability}

Rater training was conducted with the Tubbs \& Moss (1987) text Human Communication, fifth edition. A text page was selected at random and coded according to the instructions set out in "Procedures". Training continued until a $95 \%$ agreement occurred.

Inter-rater reliability was calculated from rater agreement on instances of behavior identification, such that 
the percent of agreement equaled the number of compatible identifications divided by the total number of unique units coded.

$$
95 \%=\frac{19 \neq \text { of agreement in identification }}{20 \text { total } \# \text { of unique units coded }}
$$

Intra-rater reliability was calculated as described above and reevaluated after a period of 10 days. There was $97 \%$ rater consistency.

$$
97 \%=\frac{181 \# \text { of agreement in identification }}{185 \text { total \# of unique units coded }}
$$

\section{Collating Process}

Twelve skills categories were obtained from the behavioral data found in the text. An inductive sorting process was used. These categories consisted of "self disclosure," "clarification," "kinesics," "paralanguage," "eye contact," "smile and frown," "proxemics," "affect displays," "silence," "haptics," "turn-taking," "head nods and shakes." Each skill behavior observation and its associated competency was recorded on a individual $3 \times 5$ index card. Upon completion of the coding process, the cards were then collated into homogeneous groups. Each group was then labeled. The label/category represented the domain within which each behavior was studied within the field of speech Communication.

For example, all behaviors that spoke to posture were stacked together, all behaviors that mentioned hands or hand 
gestures were similarly stacked. At the end of this process, groups of behaviors were placed together according to their similarities. For example, a group of cards indicating behaviors that referred to body movements were labeled Kinesics. This group then became a category labeled Kinesics. All of the categories that did emerge were found subsequently in Adler and Rodman's (1991) textbook glossary or in Devito's (1986) Communication Handbook, the reference text referred to in chapters I, II, and III.

INDENTIFICATION OF SKILLS AND PAIRED COMPETENCIES

For ease of presentation the data has been presented in connection with the category name. For each category of skill behavior, the definition, table of observations of skills and their associated competency language, and a narrative description of the category contents are presented.

\section{Self Disclosure}

"The process of deliberately revealing information about oneself that is significant and that would not normally be known by others" (Adler \& Rodman, 1991, p.461).

Self disclosure is one of five verbal behaviors found in the content analysis. 
There were 20 distinct observations (see Table I), 8 of which were referenced by the single term "disclosure." of these 8 behaviors, outcomes were expressed in terms of: closeness, regard, validation, confirmation, and reciprocity. The remaining 12 behaviors were expressed in phrases. Of these behaviors, 4 referenced the act of "revealing" something to the other, with the associated outcomes divided among positives, "favorable impressions" and "making ourselves look good," a negative, "unproductive" and a neutral "increase control." The observation which was coded "volunteering personal information" and its associated outcome, "relationship maintenance and enhancement" summarized the disclosure cluster.

\section{Clarification}

Questioning and paraphrasing for clarity. Questioning is feedback that usually requests the speaker to supply additional information in order to clarify or expand the receiver's understanding. Also, a style of helping in which the receiver seeks additional information from the sender (p.460). Paraphrasing is feedback in which the receiver rewords the speaker's thoughts and feelings. Can be used to verify understanding, demonstrate empathy, and help others solve their problems (Adler \& Rodman, 1991, p.459). There were 36 distinct observations (see Table II), 14 of which were referenced by the single term "questioning" 
and 9 by the single term "paraphrasing". The associated outcomes of the "questioning" behaviors that were coded include phrases such as "becomes a strategy," "trap or indirectly guide," "disguising advice or criticism," "elaborate," and "define vague ideas." The outcomes of the "paraphrasing" behaviors coded include 4 references to "understanding". Other associated outcomes referred to "empathy," "accuracy," and "problem solving." of the 11 phrases associated with clarification behaviors, 4 were listed as "use supporting material" and were coded for public speaking, 2 were "perception checking statements," and 2 were checking "with others" and for "understanding." The associated outcomes for these behaviors revolve around the concept of "prevent misinterpretations." of the 36 codings of associated outcomes for the clarification cluster, 8 spoke directly to the issue of clarity.

\section{Kinesics}

"The study of body movement, gesture, and posture" (Adler \& Rodman, 1991, p.458).

There were 32 distinct behavioral observations (see Table III). of these, 10 were behaviors which dealt with posture, 4 with shoulders and shrugs, 7 were references to hands and hand gesturing, and 11 behaviors addressed "fidgeting," "preening," "walking," and "gesturing." of outcomes associated with postures, most were directed toward 
public speaking messages, such as "make you more visible and increase audience contact," but several addressed diadic interaction outcomes, as in, "non-threatening" and "more empathic." The 4 observations that addressed shoulders and shrugs were accompanied by outcomes of "non-verbal substituting," and "doubt sincerity." of the 7 observations made that included hands and fingers, all of the associated outcomes were a form of message to the receiver, such as "snapping your fingers" meant "idea occurring," and "hands in your pockets" meant "discount what you say, react negatively." of the 11 phrases signifying associated outcomes for fidgeting, preening and walking slowly, most were "signals" to the receiver, such as, "signal of discomfort or uneasiness," "signal interest in other" and "communicates vulnerability."

\section{Paralanguage}

"Aspects of speech that are superimposed on and that are spread over other elements, for example, stress, pitch, pause. A general term for vocal but nonverbal behavior." Meaning that is superimposed over speech sounds (Devito, 1986, p.309).

Total observations in this category were 21 (see Table IV). Tone was a factor in 4 behavioral observations, with outcomes focused on confirming and disconfirming messages. Pitch was coded 5 times, with the associated outcomes 
clustered around "emphasis" on the messages. Phrases that dealt with speech speed or rate totaled 4 , the focus of which centered on speeding up the normal speech rate for public speaking. Volume accounted for 3 of the 21

observations and the outcomes were concerned with "emphasis on ideas or words". The remaining 4 behaviors in the Paralanguage cluster represented fluctuation in the behaviors listed above and the outcomes spoke to issues of "sadness," "concealing fear or anger," and "change meaning of a simple sentence." A single observation was made of a sigh and had an outcome that "substituted for verbal answers."

\section{Eye contact}

Looking at another person's eyes. "Gaze is the nonverbal behavior of looking, most often used to refer specifically to looking into another person's eyes or face" (Devito, 1986, p.137).

There were 20 distinct behavioral observations in this cluster (see Table V). The phrases that stated "eye contact" specifically totaled 11, of which 3 outcomes made statements of increases in "interest," 1 "confirming or disconfirming," and the others varied from "comfort" to "perception checking." Behaviors referencing "gaze", "glance" and "stare," range in outcomes from "being attentive," "appropriate vs. uncomfortable" to 
"threatening." Behaviors coded for non-eye contact, such as "looking away," "Down cast expression," and "close your eyes" all reference the outcome "avoidance" in some form.

Smile

A smile is a facial feature that is used to demonstrate nonaggressive intentions, to indicate pleasure and satisfaction, and to indicate embarrassment or acceptance of a not-so-favored alternative. Smiling behavior, of course, does not occur in isolation but rather accompanies a number of other nonverbal gestures. The eyes generally change, usually getting wider, the pupils dilate, and the body can seem more relaxed and at ease (DeVito, 1986, p.297). Frowns were coded here as the opposite of smiles or anti-smiles.

From the 13 coded observations (see Table VI), 4 were listed under the term "smile," with the associated outcomes ranging from "appearance of being attentive," to "positive emotion." The behavior "a warm smile" displayed an outcome of "involvement with message." There were 3 coded observations of "smiling" with outcome of "confirmation," "convince others that we're happy," and "likes idea or amusing." There are 4 codings of frown behavior, with associated outcomes that include "substitute for verbal answer," "confusion or disagreement," and "negative feelings." 


\section{Proxemics}

"The study of how people and animals use space" (Adler \& Rodman, 1991, p.460).

of the 17 coded observations (see Table VII), the observable behaviors involved 3 uses of intimate space, 2 personal space, 2 social space, and 5 public space. The outcomes associated with intimate space included "other partner feels uncomfortable," "does not retreat" and "sign of trust and lowered defenses." Social space outcomes are "messages of confirming or disconfirming" and "feels threatened." Observations of social space are associated with "less relaxed type of conversation," and "avoiding contact." Public distance brought outcomes associated with public speaking control, such as "express your confidence," and "extend the action zone." The last 6 observations in this table are associated with avoiding, such as "increased distance" and "leave the room." The outcomes of these behaviors are coded as "confirming or disconfirming," "less friendly, less talkative, and less acquainted," and ends with "avoiding contact."

\section{Affect Displays}

"Movements of the facial area that convey emotional meaning, for example, anger, fear, and surprise" (Devito, 1986, p.7). 
of the 4 behavioral observations made in this cluster (see Table VIII), 3 were specific displays, "smirk," "dirty look" and "expression on your face as if you were about to be shot." The 3 associated outcomes consisted of "doubt," "displeasure," and "discount what you say." The less specific behavior was "facial expression" and its outcome was "comfort."

\section{Silence}

"Like the eyes and face or hands, silence can be used to communicate varied emotional responses, to allow time for the message to sink in, or to signal turn taking" (Devito, 1986, p.294).

There were 5 discrete observations that made the silence cluster (see Table IX), 3 of which are coded as "get quite" and "remaining quite." The associated outcomes of quiet behaviors are "conflict," "distrustful and detached," and "valued vs. uncomfortable." The 2 remaining behaviors, "silence" and "silent treatment" are associated with terms of "awkward, embarrassing, and displeasure."

Haptics

"The study of the role of touch in communications" (DeVito, 1986, p.147).

There are 8 coded observations (see Table X), 5 of which reference "touch." The outcomes of touching are, 
"healthy development," "increase self disclosure, verbalization, and increases compliance." The 3 remaining observations include, "firm handshakes," and "hugs, kisses, and playful wrestling," with associated outcomes of "straightforward," "intimacy," and "expressions of love."

\section{Turn Taking}

The conversational behavior in which interactants exchange the roles of source and receiver. Turn-Taking Cues are the nonverbal and verbal behaviors that communicate the desire to exchange the roles of source and receiver, for example, raising an index finger, opening one's eyes wide, pursing one's lips, verbal starts such as "I..." (Devito, 1986, p.327).

of the 3 behavioral observations (see Table XI), 2 were directly related to auditory cues, such as "rising then falling or draw out intonation pattern, then stop talking." The single behavior of "turn taking" had an outcome of "awkwardness."

\section{Head Nods}

A substitute for a verbal response. Head shakes, side to side movement of the head indicating a negative. There are 5 discrete observations (see Table XII), 3 of which involve "nods" as behaviors with outcomes related to listening, such as "message received," "appearance of being 
attentive," and "avoid listening." "Yes and No" were 2 of the associated outcomes of the behaviors coded.

CONTEXT

The context in which scorable skills appeared in the text were also recorded. Joseph DeVito (1986) defines context as "the physical, social-psychological, and temporal environment in which communication takes place and which exert influence on the form and content of communication" (p.79). The Alder \& Rodman (1991) text addressed topics in the interpersonal, intercultural, group, and public speaking environments. The context within which each observation was made was noted during the coding. Most coded behaviors occurred in the interpersonal context. Second most frequent was the public context, followed by the group context. Almost exclusively, skills were not specific to or embedded within a particular context. The single exception consisted of hand gestures. Within the kinesics category, hand gestures were linked to the intercultural context as a function of specific intercultural differences in gesture.

\section{SUMMARY}

Relative Number of Verbal and Nonverbal Observations The analysis of the text with respect to observable skill behaviors produced 123 nonverbal skills observations 
and 61 verbal skills observations. These observations gave rise to nine nonverbal categories of skill behaviors and three verbal categories of skill behaviors. Self-disclosure, clarification, and silence are the only verbal categories that were represented as discrete, observable, teachable and purposeful.

Repeated competencies

The behavioral skills data collected in the content analysis naturally clustered into categories as previously described. The outcomes linked to the skills behaviors, were quite variable; however, three patterns that warrant further comment, did emerge from these outcomes or competencies. They consisted of the language of "confirming/disconfirming," "comfortable/uncomfortable," and "emphasis." Confirming/disconfirming competencies were linked with seven different specific skill behaviors; "waving," "tone of voice," "eye contact," "smiling," "smile," "use of personal space," and "approaching or avoiding." Those competency-related skill behaviors ranged across five of the twelve skill categories. Comfortable/uncomfortable outcomes were associated with seven different specific skill behaviors; "posture," "fidgeting: massages, rubs, holds, fidgets, pinches, picks, or otherwise manipulates other body parts," "vocal tone," "stand near one's partner," "stand," "facial expression," 
and "remaining quiet." These behaviors fell under five skill categories. Finally, an emphasis competency was coded five times and paired with skill behaviors of "pointing an accusing finger," "change in volume, pitch or rate," "pause or speed up," "volume," and "whisper or scream." These behaviors reflected two skill categories, namely kinesics and paralanguage.

\section{Task/Relational outcomes}

A pattern of task/relational outcomes surfaced, in which 131 codeable behaviors were linked with relational outcomes and 53 behaviors were associated with task-related outcomes. The largest number of unbalanced task-torelational observations was contributed by the paralanguage skill category in which 13 outcomes were relational in nature, compared to 8 task-related competencies. In 10 of the 12 skills categories, relational competency observations exceeded task competency observations. Task competency observations exceeded relational observations in only the clarification and haptics, resulting in task versus relational observations of 19 to 17 and 5 to 3 , respectively. 
TABLE I

SELF DISCLOSURE

\begin{tabular}{|c|c|c|}
\hline & Observable Behavior & $\begin{array}{l}\text { Associated } \\
\text { outcome/competencies }\end{array}$ \\
\hline 1. & Disclosure & developing relationship \\
\hline 2. & & closeness \\
\hline 3. & & regard \\
\hline 4 . & & $\begin{array}{l}\text { can be helpful or cause } \\
\text { harm }\end{array}$ \\
\hline 5. & & $\begin{array}{l}\text { validation of behavior and } \\
\text { confirmation }\end{array}$ \\
\hline 6. & & stay healthy and develop \\
\hline 7. & & achieve desired result \\
\hline 8. & & reciprocity \\
\hline 9. & Reveal information & make ourselves look good \\
\hline 10. & $\begin{array}{l}\text { Discourage feedback but } \\
\text { disclose freely }\end{array}$ & seem self centered \\
\hline 11. & $\begin{array}{l}\text { Seek opinions and } \\
\text { disclose own }\end{array}$ & $\begin{array}{l}\text { intimidating and } \\
\text { overwhelming or develops a } \\
\text { relationship }\end{array}$ \\
\hline 12 . & $\begin{array}{l}\text { Reveal yourself too } \\
\text { much }\end{array}$ & unproductive \\
\hline 13. & Unequal self-disclosure & unbalanced relationship \\
\hline 14 . & $\begin{array}{l}\text { Sharing private } \\
\text { information }\end{array}$ & respect and trust \\
\hline 15. & $\begin{array}{l}\text { Talk more about your } \\
\text { own feelings and } \\
\text { personal experiences }\end{array}$ & $\begin{array}{l}\text { Less formal and more } \\
\text { intimate }\end{array}$ \\
\hline 16. & $\begin{array}{l}\text { Men talk about } \\
\text { themselves }\end{array}$ & $\begin{array}{l}\text { conversations run smoothly } \\
\text { and women adapt }\end{array}$ \\
\hline 17 . & Reveal yourself & favorable impression \\
\hline
\end{tabular}


TABLE I

SELF DISCLOSURE

(continued)

\begin{tabular}{||l|l|l||}
\hline & $\begin{array}{l}\text { Observable Behavior. } \\
\text { Revealing personal } \\
\text { information }\end{array}$ & $\begin{array}{l}\text { Associated } \\
\text { Outcome/competencies . }\end{array}$ \\
\hline 19. & $\begin{array}{l}\text { Volunteering personal } \\
\text { information }\end{array}$ & $\begin{array}{l}\text { relationship maintenance } \\
\text { and enhancement }\end{array}$ \\
\hline 20. & & self clarification \\
\hline
\end{tabular}


TABLE II

CLARIFICATION

\begin{tabular}{|c|c|c|}
\hline & Observable Behavior & $\begin{array}{l}\text { Associated } \\
\text { Outcome/Competencies }\end{array}$ \\
\hline 1. & Questioning & becomes a strategy \\
\hline 2. & & trap or indirectly guide \\
\hline 3. & & verbal clarification \\
\hline 4. & & repeat your instructions \\
\hline 5. & & $\begin{array}{l}\text { find out the other's real } \\
\text { position }\end{array}$ \\
\hline 6. & & clarify and help clarify \\
\hline 7. & & elaborate \\
\hline 8. & & verify information \\
\hline 9. & & understand clearly \\
\hline 10. & & define vague ideas \\
\hline 11. & & $\begin{array}{l}\text { disguising advice or } \\
\text { criticism }\end{array}$ \\
\hline 12. & & lead to a long digression \\
\hline 13 . & & $\begin{array}{l}\text { may lead to a wild goose } \\
\text { chase }\end{array}$ \\
\hline 14 . & & $\begin{array}{l}\text { encourage examination in } \\
\text { more detail }\end{array}$ \\
\hline 15 . & $\begin{array}{l}\text { Skills of paraphrasing } \\
\text { and questioning }\end{array}$ & $\begin{array}{l}\text { figure out what the } \\
\text { speaker is driving at }\end{array}$ \\
\hline 16. & Paraphrasing & $\begin{array}{l}\text { provide check on } \\
\text { understanding }\end{array}$ \\
\hline 17 . & & $\begin{array}{l}\text { sort out and solve } \\
\text { problems }\end{array}$ \\
\hline 18. & & clarify idea \\
\hline 19. & & whether you understand \\
\hline 20. & & accuracy double check \\
\hline 21. & & understanding \\
\hline
\end{tabular}


TABLE II

CLARIFICATION

(continued)

\begin{tabular}{|c|c|c|}
\hline & Observable Behavior & $\begin{array}{l}\text { Associated } \\
\text { outcome/competenciles. }\end{array}$ \\
\hline 22 . & & $\begin{array}{l}\text { avoid tendency to judge } \\
\text { before understanding }\end{array}$ \\
\hline 23. & & explore feelings in depth \\
\hline 24. & & show empathy \\
\hline 25 . & $\begin{array}{l}\text { Talking about beliefs, } \\
\text { opinions, thoughts and } \\
\text { attitudes }\end{array}$ & self-clarification \\
\hline 26. & Checking with others & $\begin{array}{l}\text { find out the other's real } \\
\text { position }\end{array}$ \\
\hline 27 . & $\begin{array}{l}\text { Perception checking } \\
\text { statements }\end{array}$ & prevent misinterpretations \\
\hline 28 . & & $\begin{array}{l}\text { test the accuracy of } \\
\text { inferences }\end{array}$ \\
\hline 29. & Check understanding & misunderstanding is small \\
\hline 30. & Negotiate the meaning & $\begin{array}{l}\text { clarify and discover } \\
\text { problems }\end{array}$ \\
\hline 31. & Use supporting material & clarify \\
\hline 32. & & memorable \\
\hline 33. & & to prove the truth \\
\hline 34. & & $\begin{array}{l}\text { to clarify, to make } \\
\text { interesting and to make } \\
\text { memorable }\end{array}$ \\
\hline 35. & & catch audience's attention \\
\hline 36. & Use quotations & prove a point \\
\hline
\end{tabular}


TABLE III

KINESICS

\begin{tabular}{|c|c|c|}
\hline & Observable Behavior & $\begin{array}{l}\text { Associated } \\
\text { Outcome/Competencies }\end{array}$ \\
\hline 1. & stand with good posture & breathe well \\
\hline 2 . & $\begin{array}{l}\text { Standing with spine } \\
\text { straight, shoulders } \\
\text { relatively squared off } \\
\text { and feet angled out }\end{array}$ & $\begin{array}{l}\text { keep your body from } \\
\text { falling over sideways }\end{array}$ \\
\hline 3. & Standing up straight & $\begin{array}{l}\text { make you more visible and } \\
\text { increase audience contact }\end{array}$ \\
\hline 4. & Posture & comfort \\
\hline 5 . & Informal posture & $\begin{array}{l}\text { encourage audience to } \\
\text { relax }\end{array}$ \\
\hline 6. & slouched over & $\begin{array}{l}\text { likely to discount what } \\
\text { you say, react negatively }\end{array}$ \\
\hline 7. & Take relaxed postures & non-threatening \\
\hline 8 . & $\begin{array}{l}\text { Mirroring the posture } \\
\text { of another }\end{array}$ & positive consequences \\
\hline 9. & Posture echoes & more empathic \\
\hline 10. & slumping shoulders & contradict our smiles \\
\hline 12. & Shrug your shoulders & non-verbal substituting \\
\hline 13. & Shrug & doubt sincerity \\
\hline 14. & & "I don't know" \\
\hline 15 . & $\begin{array}{l}\text { Pointing an accusing } \\
\text { finger }\end{array}$ & add emphasis \\
\hline 16. & Snapping your fingers & idea occurring \\
\hline 17. & Scratching the head & searching for an idea \\
\hline 18. & A hand to the ear & I can't hear you \\
\hline 19. & The "okay" gesture & $\begin{array}{l}\text { cheery affirmation vs. } \\
\text { you're worth zero or a } \\
\text { sexual invitation }\end{array}$ \\
\hline 20 . & Hands in your pockets & $\begin{array}{l}\text { discount what you say, } \\
\text { react negatively }\end{array}$ \\
\hline
\end{tabular}


TABLE III

KINESICS

(continued)

\begin{tabular}{|c|c|c|}
\hline & observable Behavior? & $\begin{array}{l}\text { Associlated } \\
\text { out come/ Competencies. }\end{array}$ \\
\hline 21. & Waving & confirmation \\
\hline 22. & & hello or goodbye \\
\hline 23. & Lack of gesturing & $\begin{array}{l}\text { lack of interest, low } \\
\text { enthusiasm, sadness, or } \\
\text { boredom }\end{array}$ \\
\hline 24. & Tighten up & threatened \\
\hline 25. & Rigid, tense appearing & lower status \\
\hline 26. & $\begin{array}{l}\text { Fidgeting: massages, } \\
\text { rubs, holds, fidgets, } \\
\text { pinches, picks, or } \\
\text { otherwise manipulates } \\
\text { other body parts }\end{array}$ & $\begin{array}{l}\text { signal of discomfort or } \\
\text { uneasiness }\end{array}$ \\
\hline 27. & $\begin{array}{l}\text { Preening behaviors: } \\
\text { stroking or combing the } \\
\text { hair, glancing in a } \\
\text { mirror and rearranging } \\
\text { the clothing }\end{array}$ & signal interest in other \\
\hline 28 . & $\begin{array}{l}\text { Walk slowly and } \\
\text { tentatively, stare at } \\
\text { the ground, move arms } \\
\text { and legs in short jerky } \\
\text { motions }\end{array}$ & communicates vulnerability \\
\hline 29. & $\begin{array}{l}\text { Sprawl on tabletops } \\
\text { and/or slouch against } \\
\text { blackboards }\end{array}$ & $\begin{array}{l}\text { effectiveness is usually } \\
\text { in spite of posture }\end{array}$ \\
\hline 30. & More relaxed & higher status \\
\hline 31. & Withdraw into a ball & avoiding contact \\
\hline 32 . & A smirk, deadpan, scowl & $\begin{array}{l}\text { involvement with your } \\
\text { messages }\end{array}$ \\
\hline
\end{tabular}


TABLE IV

PARALANGUAGE

\begin{tabular}{|c|c|c|}
\hline & Observable Behavior & $\begin{array}{l}\text { Associated } \\
\text { Outcome/Competencies }\end{array}$ \\
\hline 1. & Tone of voice & $\begin{array}{l}\text { confirming vs. } \\
\text { disconfirming }\end{array}$ \\
\hline 2. & Vocal tone & comfort \\
\hline 3 . & Right tone of voice & $\begin{array}{l}\text { match the content of } \\
\text { verbal message }\end{array}$ \\
\hline 4. & Light tone of voice & doubt sincerity \\
\hline 5. & $\begin{array}{l}\text { Pitch, the highness or } \\
\text { lowness of your voice }\end{array}$ & squeak or more in control \\
\hline 6. & Pitch & speed up or become louder \\
\hline 7. & Range in pitch & $\begin{array}{l}\text { singsong quality or overly } \\
\text { dramatic }\end{array}$ \\
\hline 8 . & Control your pitch & $\begin{array}{l}\text { talking with them rather } \\
\text { than performing }\end{array}$ \\
\hline 9 . & $\begin{array}{l}\text { Change in volume, pitch } \\
\text { or rate }\end{array}$ & emphasis \\
\hline 10. & Normal speaking speed & $\begin{array}{l}\text { lull your audience to } \\
\text { sleep or be unintelligible }\end{array}$ \\
\hline 11. & Boost in speaking rates & mistakes \\
\hline 12. & Speed up delivery & $\begin{array}{l}\text { rapid almost machine gun } \\
\text { style }\end{array}$ \\
\hline 13. & Pause or speed up & suggest emphasis \\
\hline 14. & Volume & emphasize an idea \\
\hline 15. & Whisper or scream & emphasized words \\
\hline 16. & $\begin{array}{l}\text { Loud enough, not loud } \\
\text { enough, fade off at the } \\
\text { end of a thought or } \\
\text { mumbling }\end{array}$ & $\begin{array}{l}\text { gain or loss of audience } \\
\text { contact }\end{array}$ \\
\hline 17. & $\begin{array}{l}\text { Quieter, lower pitched } \\
\text { speech at a slower rate }\end{array}$ & sadness \\
\hline 18. & $\begin{array}{l}\text { Voice sounds higher and } \\
\text { louder; rate increases }\end{array}$ & conceal fear or anger \\
\hline
\end{tabular}


TABLE IV

\section{PARALANGUAGE}

(continued)

\begin{tabular}{|c|c|c|}
\hline & observable Behavior. & $\begin{array}{l}\text { Associlated } \\
\text { outcome/Competencles. }\end{array}$ \\
\hline 19. & $\begin{array}{l}\text { Shifting the emphasis } \\
\text { from word to word }\end{array}$ & $\begin{array}{l}\text { change meaning of a simple } \\
\text { sentence }\end{array}$ \\
\hline 20 . & $\begin{array}{l}\text { stressing certain words } \\
\text { with the voice }\end{array}$ & add nonverbal accents \\
\hline 21. & Sigh & $\begin{array}{l}\text { substitute for verbal } \\
\text { answer }\end{array}$ \\
\hline
\end{tabular}


TABLE V

EYE CONTACT

\begin{tabular}{|c|c|c|}
\hline & Observable Behavior & $\begin{array}{l}\text { Associated } \\
\text { Outcome/Competencies }\end{array}$ \\
\hline 1. & $\begin{array}{l}\text { Establishing eye } \\
\text { contact }\end{array}$ & showing interest \\
\hline 2. & Eye contact & measure of listening \\
\hline 3. & & message received \\
\hline 4. & & control nervousness \\
\hline 5 . & & $\begin{array}{l}\text { confirming or } \\
\text { disconfirming }\end{array}$ \\
\hline 6. & & comfort \\
\hline 7. & & increase interest in you \\
\hline 8. & More eye contact & more interest \\
\hline 9. & Direct eye contact & test perceptions \\
\hline 10. & Maintain eye contact & want something \\
\hline 11. & Look you in the eye & $\begin{array}{l}\text { appearance of being } \\
\text { attentive }\end{array}$ \\
\hline 12 . & Direct gaze & $\begin{array}{l}\text { appropriate vs. } \\
\text { uncomfortable }\end{array}$ \\
\hline 13. & $\begin{array}{l}\text { Meeting someone's } \\
\text { glance }\end{array}$ & sign of involvement \\
\hline 14. & Being stared at & threatening \\
\hline 15. & Looking away & desire to avoid contact \\
\hline 16. & Glance away & approach other people \\
\hline 17. & Glancing away & avoid a question \\
\hline 18. & Down cast expression & avoidance or dishonesty \\
\hline 19. & Close your eyes & avoiding contact \\
\hline 20. & Eye contact & more audience control \\
\hline
\end{tabular}


TABLE VI

SMILE AND FROWN

\begin{tabular}{|c|c|c|}
\hline & Observable Behavior & $\begin{array}{l}\text { Associated } \\
\text { outcome/ Competencies }\end{array}$ \\
\hline 1. & Smile & $\begin{array}{l}\text { appearance of being } \\
\text { attentive }\end{array}$ \\
\hline 2. & & message received \\
\hline 3. & & romance or politeness \\
\hline 4. & & positive emotion \\
\hline 5. & A warm smile & involvement with message \\
\hline 6. & Smiling & $\begin{array}{l}\text { convince others that we're } \\
\text { happy }\end{array}$ \\
\hline 7. & & confirmation \\
\hline 8 . & & $\begin{array}{l}\text { likes idea or amusing or } \\
\text { completely impractical } \\
\text { idea }\end{array}$ \\
\hline 9. & Smiles and laughter & positive emotions \\
\hline 10. & Smile or frown & $\begin{array}{l}\text { substitute for verbal } \\
\text { answer }\end{array}$ \\
\hline 11. & & $\begin{array}{l}\text { confirming or } \\
\text { disconfirming }\end{array}$ \\
\hline 12. & Frown & confusion or disagreement \\
\hline 13. & & negative feeling \\
\hline
\end{tabular}


TABLE VII

PROXEMICS

\begin{tabular}{|c|c|c|}
\hline & Observable Behavior & $\begin{array}{l}\text { Observable } \\
\text { outcome/Competencles }\end{array}$ \\
\hline 1. & Stand near ones partner & $\begin{array}{l}\text { the other partner feels } \\
\text { uncomfortable }\end{array}$ \\
\hline 2. & $\begin{array}{l}\text { Moves into the other's } \\
\text { intimate zone }\end{array}$ & $\begin{array}{l}\text { does not retreat or } \\
\text { withdraw to a greater } \\
\text { distance }\end{array}$ \\
\hline 3. & & $\begin{array}{l}\text { sign of trust and lowered } \\
\text { defenses }\end{array}$ \\
\hline 4. & Use of personal space & $\begin{array}{l}\text { messages of confirming for } \\
\text { disconfirming }\end{array}$ \\
\hline 5. & Invades personal space & feels threatened \\
\hline 6. & $\begin{array}{l}\text { Sitting at social } \\
\text { distance }\end{array}$ & $\begin{array}{l}\text { less relaxed type of } \\
\text { conversation }\end{array}$ \\
\hline 7 . & $\begin{array}{l}\text { Forced into crowded } \\
\text { place }\end{array}$ & draw away, avoid contact \\
\hline 8. & $\begin{array}{l}\text { Voluntarily use public } \\
\text { distance }\end{array}$ & $\begin{array}{l}\text { interested in having a } \\
\text { dialogue }\end{array}$ \\
\hline 9. & $\begin{array}{l}\text { Walk to the front of } \\
\text { your audience }\end{array}$ & express your confidence \\
\hline 10. & $\begin{array}{l}\text { Move voluntarily around } \\
\text { room }\end{array}$ & $\begin{array}{l}\text { control involuntary } \\
\text { movement and control } \\
\text { energy }\end{array}$ \\
\hline 11. & $\begin{array}{l}\text { Move forward, away or } \\
\text { side to side }\end{array}$ & extend the action zone \\
\hline 12. & Stand & comfortable \\
\hline 13. & Approaching or avoiding & $\begin{array}{l}\text { confirming or } \\
\text { disconfirming }\end{array}$ \\
\hline 14 . & Increased distance & $\begin{array}{l}\text { less friendly, less } \\
\text { talkative and less } \\
\text { acquainted }\end{array}$ \\
\hline 15. & Avoiding the person & displeasure \\
\hline 16. & Walk away & react defensively \\
\hline 17. & Leave the room & avoiding contact \\
\hline
\end{tabular}


TABLE VIII

AFFECT DISPLAYS

\begin{tabular}{|c|c|c|}
\hline & Observable Behavior & $\begin{array}{l}\text { Associated } \\
\text { Outcome/Competencies }\end{array}$ \\
\hline 1. & Smirk & doubt its sincerity \\
\hline 2. & Facial expression & comfort \\
\hline 3. & Dirty look & displeasure \\
\hline 4 & $\begin{array}{l}\text { Expression on you face } \\
\text { as if you were about to } \\
\text { be shot }\end{array}$ & discount what you say \\
\hline
\end{tabular}

TABLE IX

SILENCE

\begin{tabular}{|c|l|l|}
\hline & observable Behaviors: & $\begin{array}{l}\text { Associated. } \\
\text { Outcomes / Competencies }\end{array}$ \\
\hline 1. & Silence & awkward; embarrassing \\
\hline 2. & Silent treatment & displeasure \\
\hline 3. & Get quiet & conflict \\
\hline 4. & Remaining quiet & valued vs. uncomfortable \\
\hline 5. & & distrustful and detached \\
\hline
\end{tabular}


TABLE X

HAPTICS

\begin{tabular}{|c|c|c|}
\hline & observable outcome & $\begin{array}{l}\text { Associated } \\
\text { outcome/competencies? }\end{array}$ \\
\hline 1. & Touch & $\begin{array}{l}\text { mental functioning and } \\
\text { physical health }\end{array}$ \\
\hline 2 . & & $\begin{array}{l}\text { Increase self disclosure, } \\
\text { verbalization, and } \\
\text { increases compliance }\end{array}$ \\
\hline 3. & Touching & healthy development \\
\hline 4. & Power of touch & on the job utility \\
\hline 5. & $\begin{array}{l}\text { Touched lightly on the } \\
\text { arm }\end{array}$ & more likely to cooperate \\
\hline 6. & Firm handshakes & $\begin{array}{l}\text { straightforward, decisive } \\
\text { people }\end{array}$ \\
\hline 7. & $\begin{array}{l}\text { Hugs, kisses and } \\
\text { playful wrestling }\end{array}$ & intimacy \\
\hline 8 . & & expressions of love \\
\hline
\end{tabular}

TABLE XI

TURN TAKING

\begin{tabular}{|c|c|c|}
\hline & Observable Behavior & $\begin{array}{l}\text { Associated } \\
\text { Outcome/Competencies }\end{array}$ \\
\hline 1. & Turn taking & awkwardness \\
\hline 2 . & $\begin{array}{l}\text { Rising then falling or } \\
\text { draw out intonation } \\
\text { pattern, then stop } \\
\text { talking }\end{array}$ & yield the floor \\
\hline 3 . & $\begin{array}{l}\text { Taking an audible } \\
\text { breath, using a } \\
\text { sustained, intonation } \\
\text { pattern. Avoid pauses }\end{array}$ & maintain your turn \\
\hline
\end{tabular}


TABLE XII

HEAD NODS AND SHAKES

\begin{tabular}{|c|c|c|}
\hline & observable behaviors & $\begin{array}{l}\text { Assol } 1 \mathrm{ated} \\
\text { outcomes/competencies }\end{array}$ \\
\hline 1. & Nods & message received \\
\hline 2. & & $\begin{array}{l}\text { appearance of being } \\
\text { attentive }\end{array}$ \\
\hline 3. & & avoid listening \\
\hline 4. & & "yes" \\
\hline 5. & Head shake & "no" \\
\hline
\end{tabular}


CHAPTER V

DISCUSSION

\section{IMPLICATIONS AND LIMITATIONS}

First, implications for communication theory are discussed. Second, the limitations of this study are addressed. Third, future research needed in the field of communication skills and competencies is encouraged.

\section{Implications for competency Theory}

The literature review identified communication skills associated with the competency level exhibited during a given episode of interaction. Indications are that skills are the foundation from which competency arises. This study has sought to augment the collection of research in communication competence by investigating the teachable behaviors as found in a skills level textbook.

Like other research in the communication field (Argyris, 1965, wiemann, 1977, Parks, 1985) this study sought parameters within which to study communication skills. The lack of a definition of what constitutes a skill has left a large "hole" in the field of speech 
Communication. The previous explorers of this issue have stepped to the brink of that "hole", pointed a finger at it, and then deftly jumped over it, to go on to more lofty pursuits.

In an effort to fill in the "crevasse" of knowledge about skills, Brian Spitzberg and H. Thomas Hurt (1987) discuss levels of inference, and illustrate how this has been problematic to other researchers.

Inferences can be conceptualized on a continuum from molecular to molar. Molecular judgments involve "low-level" inferences regarding relatively discrete, specific stimuli (e.g., "s/he made eye contact", "s/he asked questions"). These are low-level inferences because very little cognitive processing or "packaging" is likely to be involved in making such judgements. On the other hand, molar judgments represent "high-level" inferences regarding relatively global, subjective characteristics (e.g., "s/he was cooperative", "s/he was trustworthy") (p.28).

This study sought discrete, observable, teachable, purposeful behaviors: behaviors that would equate to skills. The parameters that were set for this study included only low-level inferences, thereby providing the groundwork for higher level inferences in subsequent work. It is the "packaging" of the inferences that remains to be studied in the future (Spitzberg \& Hurt, 1987). The clusters of behaviors provided access to labels for behaviors found in the content analysis, but did not establish a pattern of behavioral inferences that would lead to skill identification. 
With respect to the contexts in which communication skills were discussed in the textual material, this study focused on the interpersonal, intercultural, group, and public speaking contexts during the coding procedure. One result of those data was that the discussions of skills were not specific to a particular context, irrespective of the context treated in that particular section of text. For example, assume that the authors treated "establishing eye contact," in a chapter on small group behavior. There was nothing in the language of the scorable unit or even sample unit that anchored the skill in a group context, as opposed to one of the other contexts. Perhaps, in order to be useful, the context must defined by some basis other than the traditional distinctions of "communication situation." An example might be to view a behavior as it might be enacted during conflict versus during play.

\section{Limitations of the study}

Text. An unanticipated limitation of this study emerged from the nature of the text material that was examined. The content analysis of Adler \& Rodman's text proved valuable, in one way, because of the discussion of communication skills in the preface. If the student were seeking a skills level class, the authors indicate that he or she would benefit from the course. However, Adler and Rodman failed to deliver. They did not delineate the 
criteria for the nature of skills or how given skills would effect the particular competency. Adler \& Rodman's (1991) stated purpose in the preface of the book was to guide students in "developing skills that will help them communicate more effectively . . develop their understanding of communication principles and practice communication skills" (p.v). They do not set out the criteria for what constitutes a skill in anywhere in the text. Communication skills are mentioned in a general fashion (pp. 203, 242, 258, 278), but no specific behaviors are associated with the term until the end of the text, where they are listed as "the ability to ask clear questions, be direct but polite, and listen effectively" (p.330). There were 18 references to skills, but at the point of reference, only two attempts at identifying what behaviors those skills referenced were observed.

The text was written at the 11th grade level (Schneider, 1991), which suggests that it is adequate for the hybrid speech course for which it is intended. However, the examples are too simplistic and at times misleading. Each chapter's title page presented a statement that listed what a student should understand and "should be able to do". What the authors wanted the student to do was "identify, describe, rate, and evaluate." These behaviors did not relate to our coding schema nor did they translate to 
"developing skills that will help them communicate more effectively in their lives" (p.v).

skill development is not reinforced throughout the book, and is mentioned only in passing: for example "...a number of skills we will soon discuss" (p.190), but no skills, as defined here, were ever identified in that chapter. Communication skills are mentioned six times on one page (p.276), referencing the workplace, but not one behavior is listed.

Procedures. This study was limited by its lack of a suitable definition of "skills". Therefore, parameters were set for behaviors that would be first observable, second teachable, third discrete, and finally associated with some desired outcome. This then substituted for a definition in the coding procedures. As indicated above, the results were of a low-level inference, while the associated outcomes gave a very vague view of competencies. The procedures left no room for grouping several behaviors to form higher levels of inference, nor for coding skills that are implied, such as listening.

The coding units and the distance between the mention of the skill to the outcome became an issue. At times there were paragraphs between the behavior and the competency addressed by the author, which was far in excess of the three sentence limit. These occurrences were not frequent, but often enough to have possibly changed the outcome of the 
study. While the three sentence sampling unit may have been overly restrictive, such decisions in context analysis design are rarely non-arbitrary. However erring in the direction of too small a unit relieved the coder from making many more arbitrary decisions concerning the skill/competency connection.

Sampling Approach. The above comments suggest another limitation of this study. Given the challenge of an inquiry into the concept of communication skills as viewed by the discipline of speech Communication, the present study adopted an analysis of textbook material as a strategy for answering the research questions posed here. Although there is no way of confirming it, perhaps alternative texts would have provided a more fruitful approach. For example, a number of questionnaires and other instruments designed to measure communication skills could have provided the material for analysis. Another quite different approach would have entailed conducting a sample survey across instructors in the field of speech communication. Finally, given a more ambitious research agenda than a Master's thesis along with the accompanying needed resources, a number of texts might have been selected for content analysis, thereby reducing the impact of whatever nonrepresentative characteristics that the Adler and Rodman work presented. At any rate, this discussion suggests future research possibilities. 
FUTURE RESEARCH

Skills reflect the transition from knowing to doing (Spitzberg \& Cupach, 1984). Three questions to consider for future research: 1) What are the parameters for communication skills which will facilitate identification? 2) How are relevant skills best developed? 3) What skills are relevant to behaving competently in which situations? The first question asks for some standard by which skills can be identified. Without a model to guide identification, researchers will continue to cover the same material without benefit of a common language with which to converse. The second question asks for a practical path to communication skills. The assumption is that competency can be learned given the appropriate skills. The third question readdresses the issue of identification of communication skills and how to configure a selection of skills for a person to behave competently.

In the section discussing the justification of the purpose for this study, several communication environments were mentioned that would benefit from research such as this: 1) the speech Communication discipline, 2) the employment culture, and 3) society at large. When reading a newspaper's employment section, for example, the requirement of "excellent communication skills" appears with a high frequency. Research is needed to identify 1) what exactly 
these skills are, 2) how to assess if you have them, and 3) where does a person go to learn them if they are lacking. If the employers who place these ads have a list of skills they require, it would benefit everyone to know what is on this list. Are the behaviors that employers need connected with answering phones, typing, and writing memos, or does the list contain terms such as perception checking, paraphrasing, and active listening? The term "communication skills" is frequently used but few scholars have identified what behaviors or cluster of behaviors constitute the defining criteria of a given skill.

Research investigating skill behaviors from the molecular to the molar level, and encompassing the continuum in some fashion, would be of great value to the communication field. Behaviors can be pointed to and identified, but the term "skill" is a standard by which behaviors could be identified. "skill" is an abstraction. Issues concerning competencies have been researched ad nauseam, but the foundation for competency is skill, which has yet to be fully defined, either conceptually or operationally. 
REFERENCES

Adler, R.B. \& Rodman, G. (1991). Understanding human communication. Fort Worth: Holt, Rinehart \& Wilton.

Allen, R.R. \& Wood, R.S. (1978). Beyond reading and writing to communication competence. Communication Education. 286-292.

Argyle, M. (1967). The psychology of interpersonal behaviour. London: Cox \& Wyman.

Argyle, M. (1968). Social interaction. London: Tavistock.

Argyris, C. (1962). Interpersonal competence and organizational effectiveness. Homewood, IL: Irwin.

Argyris, C. (1968a). The nature of competence-acquisition activities and their relationship to therapy. In W.G.Bennis, E.H.Schein, F.I.Steele, \& D.E.Berlew (Eds.), Interpersonal dynamics: Essays and readings on human interaction. Homewood, IL: Dorsey Press.

Argyris, C. (1968b). Interpersonal competence and organizational effectiveness. In W.G.Bennis, E.H.Schein, F.I.Steele, \& D.E.Berlew (Eds.), Interpersonal dynamics: Essays and readings on human interaction. Homewood, IL: Dorsey Press.

Aristotle (1980). The works of Aristotle: Rhetoric. In R.M.Hutchins (Ed.) \& W.R.Roberts (Trans.). Great books of the western world: Aristotle II (Vol.9, pp.593680). Chicago, IL: Encyclopaedia Britannica. (Original translation published 1952).

Backlund, P.M. (1982). A response to "communication competence and performance: A research and pedagogical perspective". Communication Education. 365-366.

Backlund, P.M., Booth, J., Moore, M., Parks, A.M., VanRheenen, D. (1982). A national survey of state practices in speaking and listening skill assessment. Communication Education, 125-129.

Bochner, A.P. \& Kelley, C.W. (1974). Interpersonal competence: Rational, philosophy and implementation of a conceptual framework. Speech Teacher, 23, 279-301. 
Bochner, A.P. \& Kelley, C.W. (1974). Interpersonal competence: Rational, philosophy and implementation of a conceptual framework. Speech Teacher, 23, 279-301.

Bochner, A.P. \& Yerby, J. (1977). Factors affecting instruction in interpersonal competence. Communication Education. 26, 91-103.

Bassett, R.E., Whittington, N., \& Spicer-Staten, A. (1978). The basics in speaking and listening for high school graduates: What should be assessed? Communication Education. 293-303.

Canary, D.J. \& Spitzberg, B.H. (1987). Appropriateness and effectiveness perceptions of conflict strategies. Human Communication Research 14, 93-118.

Canary, D.J. \& Spitzberg, B.H. (1990). Attribution biases and associations between conflict strategies and competence outcomes. Communication Monographs, 57, 137151 .

Cappella, J.N. (1985). The management of conversations. Handbook of interpersonal communication. M.L.Knapp \& G.R.Miller (Eds.). Beverly Hills: Sage. 393-438.

DeVito, J.A. (1986). The communication handbook: A dictionary. New York: Harper \& Row.

Diez, M.E. (1984). Communicative competence: An interactive approach. In R.Bostrom (Ed.), Communication Yearbook 8, 56-79. Beverly Hills: Sage.

Engler-Parish, P.G. \& Miller, F.E. (1989). An exploratory relational control analysis of the employment screening interview. Western Journal of Speech Communication, $53,30-51$.

Goffman, E. (1959). The presentation of self in everyday life. Garden City, New York: Doubleday - Anchor.

Goffman, E. (1967). Interaction ritual: Essays on face-toface behavior. Garden City, New York: Anchor Doubleday.

Goffman, E. (1968). On face-work: An analysis of ritual elements in social interaction. In w.Bennis, E.Schein, F.Steele, \& D.Berlew (Eds.), Interpersonal dynamics: Essays and readings on human interaction. Homewood, IL: Dorsey. 226-249. 
Goffman, E. (1973). Facial engagements. In C.D. Mortensen (Ed), Basic readings in communication theory. New York, NY: Harper \& Row. 64-90.

Golden, J.L., Berquist, G.F., \& Coleman, W.E. (1989). The rhetoric of western thought ( 4 th ed.). Dubuque, IA: Kendall/Hunt.

Grove, T.G. (1991). Dyadic interaction: Choice and change in conversations and relationships. Dubuque, IA: William. C. Brown Publishers.

Hass, J.W. \& Seibert, J.H. (1988). In search of communication competence. Paper presented at the annual meeting of the International Communication Association, New orleans, LA.

Hymes, D. (1971). On communicative competence. In J. Pride \& J. Holmes (Eds.), Sociolinguistics. London: Penguin Books.

Littlejohn, S.W., \& Jabusch, D.M. (1982). Communication competence: Model and application. Journal of Applied Communication Research, 10, 29-37.

McCroskey, J.C. (1982). Communication competence and performance: A research and pedagogical perspective. Communication Education, 31, 1-7.

Muchmore, J. \& Galvin, K. (1983). A report of the task force on career competencies in oral communication skills for community college students seeking immediate entry into the work force. Communication Education, 32, 207-220.

Parks, M. R. (1985). Interpersonal competence and the quest for personal competence. In M.L. Knapp \& G.R. Miller (Eds.), Handbook of interpersonal communication. Beverly Hills, CA: Sage.

Portland State University Bulletin 1991-92. Vol.25 No.5, Aug 1991. Portland, OR: PSU.

Rubin, R.B. (1982). Assessing speaking and listening competence at the college level: The communication competency assessment instrument. Communication Education. 19-32.

Samter, W. \& Burleson, B. (1990). Evaluations of communication skills as predictors of peer acceptance in a group living situation. Communication studies, 41 , 331-325. 
Schneider, D.E. (1991). An analysis of readability levels of contemporary textbooks that employ a hybrid approach to the basic communication course. Communication Education, 2, 165-171.

Spitzberg, B. H. (1983). Communication competence as knowledge, skill and impression. Communication Education, 32, 323-327.

Spitzberg, B.H. \& Brunner, C.C. (1991). Toward a theoretical integration of context and competence inference research. Western Journal of Speech Communication, 55, 28-46.

Spitzberg, B.H. \& Canary, D.J. (1985). Loneliness and relationally competent communication. Journal of Social and Personal Relationships, 2, 387-402.

Spitzberg, B.H. \& Cupach, W.R. (1984). Interpersonal communication competence. Beverly Hills, CA: Sage.

Spitzberg, B.H. , \& Cupach, W.R. (1991). Toward a theoretical integration of context and competence inference research. Western Journal of Speech Communication. 55, 28-46.

Spitzberg, B.H. \& Hurt, H.T. (1987). The measurement of interpersonal skills in instructional contexts. Communication Education, 1, 28-45.

Taylor, A., Meyer, A., Rosegrant, T., \& Samples, B.T. (1989). Communicating (5th ed.). Englewood Cliffs, NJ: Prentice Hall.

Trank, D.M. \& Steele, J.M. (1983). Measurable effects of a communication skills course: An initial study. communication Education, 32, 227-235.

Tubbs, S.L. \& Moss, S. (1987). Human Communication (5th ed.). NY: Random House.

Van Hoeven, S.A. (1985). What we know about the development of communication competence. Central states Speech Journal, 36, 33-38.

White, R.W. (1959). Motivation reconsidered: The concept of competence. Psychological Review, 66, 297-333. 
White, R.W. (1968). Sense of interpersonal competence: Two studies and some reflections on origins. In G.W.Schein, F.I.Steele \& D.E.Berlew (Eds.), Interpersonal dynamics: Essays and readings on human interaction. Homewood, IL: Dorsey Press.

Wiemann, J.M. (1977). Explication and test of a model of communicative competence. Human Communication Research. $3,195-213$.

Wiemann, J.M. \& Backlund, P. (1980). Current theory and research in communicative competence. Review of Education Research, 50, 185-199.

Wiemann, J.M. \& Bradac, J.J. (1989). Metatheoretical issues in the study of communicative competence: structural and functional approaches. In B. Dervin \& J.M.Voight (Eds.), Progress in Communication Sciences, Vol.9. Norwood, NJ: Ablex.

Wilmot, W.W. (1987). Dyadic communication 3rd ed. New York: Random House. 